\title{
Preparation and optimization of Starch/Poly vinyl alcohol/ ZnO nanocomposite films applicable for food packaging
}

\section{Saeed Yari}

University of Tehran

Jamshid Mohammadi-Rovshandeh

University of Tehran

Mohsen Shahrousvand ( $\nabla$ m.shahrousvand@ut.ac.ir)

University of Tehran

\section{Research Article}

Keywords: Food packaging, Poly vinyl alcohol (PVA), Response Surface Methodology (RSM), Starch, Zinc oxide ( $\mathrm{ZnO})$

Posted Date: May 17th, 2021

DOl: https://doi.org/10.21203/rs.3.rs-526313/v1

License: (c) (i) This work is licensed under a Creative Commons Attribution 4.0 International License. Read Full License

Version of Record: A version of this preprint was published at Journal of Polymers and the Environment on September 23rd, 2021. See the published version at https://doi.org/10.1007/s10924-021-02292-2. 


\section{Preparation and optimization of Starch/Poly vinyl alcohol/ ZnO nanocomposite films applicable for food packaging}

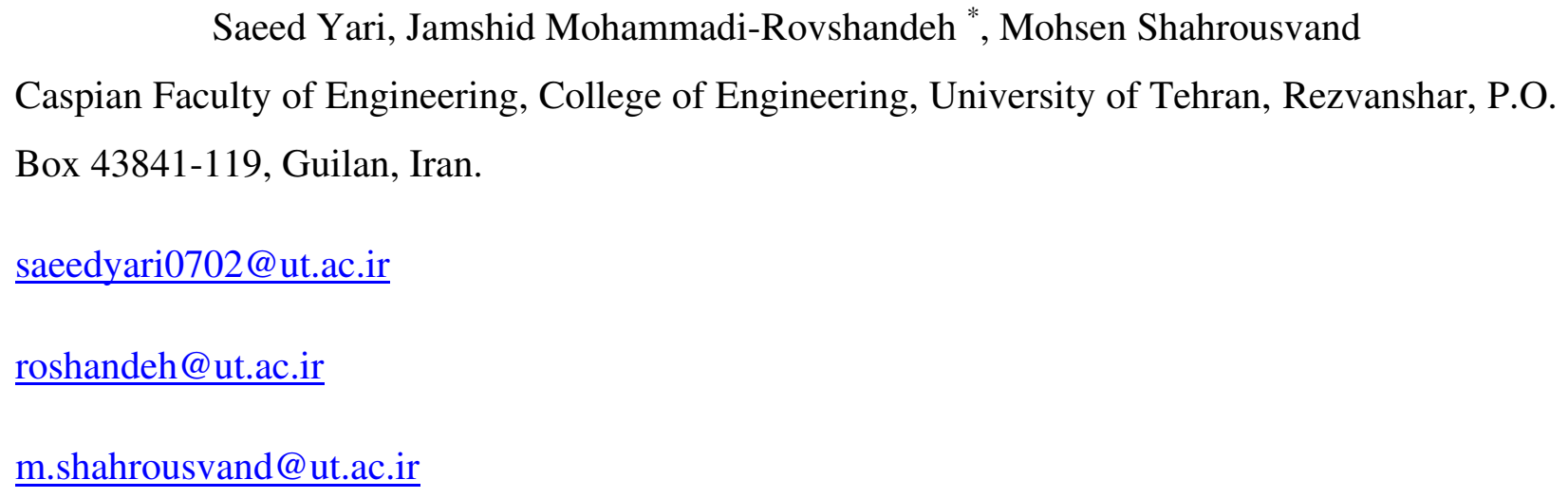

Corresponding author: Jamshid Mohammadi-Rovshandeh, Caspian Faculty of Engineering, College of Engineering, University of Tehran, Rezvanshar, P.O. Box 43841-119, Guilan, Iran, roshandeh@ut.ac.ir

Keywords: Food packaging, Poly vinyl alcohol (PVA), Response Surface Methodology (RSM), Starch, Zinc oxide ( $\mathrm{ZnO})$

(1)

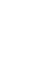

(8)

9

0

1

2

3

4

5

6

7


29 Pollution and destruction of the environment due to the accumulation of non-degradable plastics are some of the most important concerns in the world. A significant amount of this waste is related to the polymers used in food packaging. Therefore, in recent years, experts in the food

32 industry have been looking for suitable biodegradable alternatives to synthetic polymers. 33 Preparing biocompatible and biodegradable films based on starch is a good choice. In this study, 34 various factors affecting films of starch/polyvinyl alcohol (PVA)/ containing ZnO nanoparticles 35 such as the amount of starch, PVA, glycerol, and $\mathrm{ZnO}$ were evaluated by response surface methodology (RSM). Film formation, mechanical properties, swelling, solubility, and water 37 vapor permeability (WVP) were selected as responses of RSM. The results showed that 38 hydrogen bonding interactions between polyvinyl alcohol and starch improved the film 39 formation. The effect of glycerol and PVA content on the mechanical strength was contrary to 40 each other. As the amount of PVA increased, the tensile strength first decreased and then 41 increased. The value of WVP was for all Runs from 0 to $6.77 \times 10^{-8} \mathrm{gm}^{-1} \mathrm{~s}^{-1} \mathrm{~Pa}^{-1}$. Finally, films 42 with high film formation, maximum tensile strength, and high elongation at break, minimum 43 solubility, permeability, and swelling were optimized. 


\section{Introduction}

In the last 20 years, the production and use of plastics worldwide have significantly increased, and the problem of waste disposal has become more apparent $[1,2]$. The use of packaging represents $39.6 \%$ of the total demand for plastics and is the largest market in the plastics industry. However, polymers are mainly used in this field are from non-renewable sources, so they are associated with environmental pollution issues [3]. In recent years, much research has been done on food packaging using natural polymers such as starch, chitosan, cellulose, gelatin, polycaprolactone, etc. The advantages of using natural polymers are that natural polymers are biodegradable, non-toxic, and biocompatible [4-7].

Starch is one of the natural, biocompatible and biodegradable polymers widely studied by researchers because starch can form cohesive sheets when processed under certain conditions [8]. Starch does not dissolve in cold water. It does not melt in the form of common thermoplastics because its degradation temperature is lower than its melting point. Still, when exposed to shear forces, thermal energy, and softeners, its granules irreversibly lose their semicrystalline structure and become a matrix [9]. Such starch behavior has been widely used to produce biodegradable plastics. Starch is available, cost-effective, and has suitable physical and mechanical properties. However, the researchers note that despite the convenience of preparing starch films, these films may have disadvantages such as low mechanical strength compared to synthetic polymers, leading to their combination with synthetic plastics. Therefore, starch can be combined with other polymers, including polyvinyl alcohol, glycerol, and polyethylene glycol [10-12].

Polyvinyl alcohol (PVA) is a semi-crystalline polymer with unique properties, such as environmental friendliness, water solubility, and high tensile strength, widely used in the paper, packaging, and medical industries [13]. Combining starch with polyvinyl alcohol is one of the most popular biodegradable plastics that researchers have studied in recent years. The history of starch and polyvinyl alcohol films has come back to the 1980s [14]. The composition of these materials has been used in many fields such as medical engineering and packaging materials [15]. However, the non-growth of microorganisms on starch films and polyvinyl alcohol is vital to solving this problem. Antibacterial substances such as zinc oxide ( $\mathrm{ZnO})$, silver nanoparticles, copper nanoparticles, chitosan derivatives, and etc. are used [16-18]. 
Zinc is a mineral found in most foods. Among metal oxides, zinc oxide as a transition metal is one of the most widely used mineral oxides in the industry. Zinc oxide with chemical formula $\mathrm{ZnO}$, a fine-grained white powder, has a hexagonal crystalline shape that is insoluble in water. Zinc oxide is an example of the most extensively used metal oxides due to its remarkable antibacterial properties. It is not only known as a safe and secure substance but also an essential micronutrient for humans. Nano-sized $\mathrm{ZnO}$ differ in morphology and show significant antibacterial activity in a wide range of bacterial species discovered. Currently, it is used as an antibacterial agent in both micro and nanoscales. When the particle size decreases to the nanometer range, it shows significant antibacterial activity. Researchers have broadly used zinc oxide nanoparticles due to their stable physical and chemical properties, non-toxicity, and cheapness [19]. Besides, hydrogen peroxide production from the surface of zinc oxide nanoparticles is reported to cause antibacterial phenomena in them [20]. This issue has led attention to improving the properties of polymers used in food packaging [19]. Generally, with the addition of nano zinc oxide in the polyvinyl alcohol polymer matrix, the obtained nanocomposite's viscoelastic and thermal properties are improved [21]. In another work, containing chitosan, PVA, and $\mathrm{ZnO}$, structural features of this composite nanofilm was investigated and shown to enhance films' antimicrobial properties by adding $\mathrm{ZnO}$ [22].

The purpose of this study is to prepare nanocomposite films based on polyvinyl alcohol/starch/ZnO that these films can be used in the food packaging industry. Different variables individually and synergistically affect the final properties of the prepared films, which must be optimized by the experimental design methods. In this study, response surface methodology (RSM) was used for optimization affecting parameters in preparation of starchbased films. For this purpose, the amount of starch, polyvinyl alcohol, glycerol, and zinc oxide were considered as variables affecting the final properties of the films in the experimental design. Film formation, mechanical properties, swelling, solubility, and water vapor permeability (WVP) were selected as responses of RSM.

\section{Materials and methods}

\subsection{Materials}

Polyvinyl alcohol (molecular weight: 89,000-98,000 g/mol and hydrolysis degree: 99\%) with 99.7\% purity, methanol, and glycerol $\mathrm{C}_{3} \mathrm{H}_{8} \mathrm{O}_{3}$ (molecular weight: $92.9 \mathrm{~g} / \mathrm{mol}$ and boiling point: 
$298{ }^{\circ} \mathrm{C}$ ) were purchased from Merck Company. Corn starch $\left(\mathrm{C}_{6} \mathrm{H}_{10} \mathrm{O}_{5}\right)_{\mathrm{n}}$ (appearance as white powder and is insoluble in warm water) has been provided from Alborz Starch Company (Iran). $\mathrm{ZnO}$ oxide nanoparticles (average particle size of 30nm) purchased from US Nano Company (USA). Deionized distilled water was used in all stages of experiments.

\subsection{Experimental design}

Design Expert 12 software has been used for statistical design of experiments, data analysis, and process optimization. Central composite design (CCD) was used based on response surface methodology (RSM) to optimize amount of starch, PVA, glycerol, and $\mathrm{ZnO}$ nanoparticles as variables. The evaluating responses were formation, swelling, solubility, mechanical properties, and water vapor permeability (WVP). Twenty experiments were performed to determine the relationships between process parameters, i.e., PVA, ZnO glycerol, starch, and the defined responses, namely the film formation, elongation, tensile strength, and solubility, water vapor permeability, and swelling. The choice range for PVA, glycerol, and $\mathrm{ZnO}$ is shown in the Table $\mathrm{S} 1 . \mathrm{PVA}$ is a starch-dependent variable so that their total weight should be $4 \mathrm{~g}$ in each experiment. Table 1 shows the construction conditions of the CCD design, including 20 runs (14 experiments and six additional tries as center point iterations) and the experimental results obtained in each method. Each response is defined by a quadratic equation, according to Equation (1), which is related to process parameters to predict the optimal conditions for making composite films.

$$
Y=\beta_{0}+\sum_{i=1}^{k} \beta_{i} \cdot X_{i}+\sum_{i=1}^{k} \beta_{i i} \cdot X_{i}^{2}+\sum_{i \leq j}^{k} \sum_{j=1}^{k} \beta_{i j} \cdot X_{i} \cdot X_{j}+\cdots+e
$$

The interaction between process variables and responses was graphically and statistically analyzed by drawing the corresponding three-dimensional graphs and analyzing variance (ANOVA). The quality of the polynomial model was evaluated in proportion to the coefficient of determination $\left(\mathrm{R}^{2}\right)$ and Fisher's Ftest, while the model terms were evaluated with a value of $\mathrm{P}$ value (probability) with a confidence level of 95\% [23]. The matrix's total weight was fixed at 5 g (dried polymer: PVA + starch), and the percentage of glycerol and $\mathrm{ZnO}$ was calculated according to the weight of PVA/starch. The composite films were made according to the conditions in Table 1 by the solution casting method and casting of solvent.

\section{Table 1.}




\subsection{Preparation nanocomposite films based on starch / PVA / nano ZnO}

Water and ethanol are mixed in a $100 \mathrm{ml}$ beaker to add nanoparticles $(\mathrm{ZnO})$ into it. Mixture was homogenized by an ultrasonic water bath with three 20 -minute replications. In the next step, PVA, glycerol, and the starch are added to the solution and homogenized at ambient temperature for $30 \mathrm{~min}$ using a magnetic stirrer at $800 \mathrm{rpm}$. To perform intermolecular reactions, the homogenized solution placed in a hot water bath at $90{ }^{\circ} \mathrm{C}$. After $30 \mathrm{~min}$, pour the sample into a $10 \mathrm{~cm}$ diameter petri dish with a styrene dish, place it in an oven at $65{ }^{\circ} \mathrm{C}$ for 15 hours, and then dry the films gently remove from the surface of the petri dish [24].

\subsection{Film Formation}

Formation of uniform starch/PVA/ZnO films with suitable appearance was an important feature for evaluating the produced films. Film formation was a qualitative feature. Therefore, to convert it into a measurable quantity, film formation was considered between 0 and 1 . So that the number 1 was chosen for the uniform film and the number 0 was chosen for the fragmented film. Film formation was repeated three times for each experiment.

\subsection{Swelling of Starch/PVA/ZnO nanocomposite films}

The immersion method in an aqueous medium was used to evaluate the swelling of the samples $[25,26]$. Pieces in size $1 \times 1 \mathrm{~cm}^{2}$ were prepared from the sheets, and their initial weight $\left(m_{1}\right)$ was determined. The samples were then placed in glass containers containing $50 \mathrm{ml}$ of distilled water and stored at $25{ }^{\circ} \mathrm{C}$. After different times, the samples were taken from glass containers, and their surface water was gently dried with a tissue paper, and their weight was measured $\left(m_{2}\right)$ and their swelling ratio was determined based on Eq. 2:

$$
\text { Swelling }(\%)=\frac{m_{2}-m_{1}}{m_{1}} \times 100
$$

\subsection{Solubility of Starch/PVA/ZnO nanocomposite films}

Water solubility (WS) analysis was performed according to Romero et al method [27]. Square $\left(1 \times 1 \mathrm{~cm}^{2}\right)$ was prepared from each sample. They were then placed in an oven at $100{ }^{\circ} \mathrm{C}$ for 24 hours, and their weight $\left(m_{1}\right)$ was measured at the end of the drying time. The sheets were immersed in $50 \mathrm{ml}$ of distilled water at ambient temperature. After 24 hours of immersion, the film pieces were removed and transferred back into the oven at a temperature of $70{ }^{\circ} \mathrm{C}$ to dry $\left(\mathrm{m}_{2}\right)$. Water solubility was calculated using Eq. 3: 
$172 W S \%=\frac{m_{2}-m_{1}}{m_{1}} \times 100$

173

174

175

176

177

178

179

180

$182 \quad W V P=\frac{\left(\frac{\Delta m}{\Delta t}\right) L}{A . \Delta P}$

183

184

\subsection{Water vapor permeability of Starch/PVA/ZnO nanocomposite films}

The permeability of the sheets to water vapor was measured according to ASTM-E96-00 standard and the gravimetric modified method [28]. For this purpose, $10 \mathrm{~g}$ anhydrous silica gel was poured into a series of glass containers as a desiccant. These glass containers were $7 \mathrm{~cm}$ high, $3 \mathrm{~cm}$ in diameter, and completely impermeable. On the lid of these containers, samples with a diameter of $2.5 \mathrm{~cm}$ were cut and placed on the inner surface of the doors. The glass containers were weighed with their contents and placed in a desiccator containing sodium chloride saturated solution at room temperature. These containers were weighed for seven days. The rate of water vapor transfer was calculated by Eq. 4:

Where $\Delta \mathrm{m} / \Delta \mathrm{t}$ is the water vapor transmission rate $(\mathrm{g} / \mathrm{s}), \mathrm{L}$ is the film thickness $(\mathrm{cm}), \mathrm{A}$ is the area of the film which is exposed to moisture, $\Delta \mathrm{P}$ is the saturation vapor pressure of water $(\mathrm{Pa})$. The measurement was performed in triplicate.

\subsection{Mechanical properties}

To determine critical mechanical parameters such as modulus, tensile strength, and elongation at break, an Instron tensile testing apparatus (5566-Applied Science Co., Ithaca, NY) based on (ASTM D882-02) method was used [29, 30]. For each film type, at least three replicates were tested $20 \times 5 \times 0.5 \mathrm{~mm}^{3}$. The tensile velocity was considered to be $10 \mathrm{~mm} / \mathrm{min}$.

\subsection{Structural characterization of the films}

The scanning electron microscope (SEM) used (AIS 2100, Seron Technology Korea) to study the structure of starch/PVA/ZnO nanocomposites. Fourier transform infrared (FTIR) spectroscopy (Bruker Optics Ft Tensor 27, Germany) was used to detect functional groups and interactions between them in nanocomposite films. 


\section{Results and discussions}

\subsection{Formation of Starch/PVA/ZnO nanocomposite films}

Fig. 1 shows the SEM images of $\mathrm{ZnO}$ nanoparticles. As it turns out, these nanoparticles are whiskers with a thickness of about $100 \mathrm{~nm}$. Samples were prepared based on the experimental design of RSM (CCD) according to Table 1 and shown in Fig. 2. The numbers shown at each sample represent the number of Run in RSM (Table 1). To quantify the parameter of film formation, they were given numbers between 0 and 1. The number one was assigned to the sample that formed the film completely and the number zero was assigned to the sample that was fully fragmented. According to Fig. 2, for example, Run-18 was assigned by 1 and Run-20, was assigned by zero. The film formation values of the samples are reported in Table 1.

Fig. 1.

Fig. 2.

Three-dimensional diagrams of the effect of different parameters on the films formation are shown in Fig. 3. As shown in Fig. 3 (A and B), with increasing the amount of PVA, the film formation of the samples has increased, and according to Fig. 3 (B and C), it can be concluded that with increasing the amount of $\mathrm{ZnO}$, the film formation of the samples also improves. However, changes in glycerol content did not appear to have much effect on film formation based on Fig. 3 (A and C). PVA has an inherently good filmability; on the other hand, the solubility of this polymer in water is better than starch. On the other hand, several researchers have proven that strong hydrogen bonding interactions occur between PVA and starch chains $[31,32]$.

\section{Fig. 3.}

\subsection{Effect on Ultimate Tensile Strength (TS)}

The prepared samples were mechanically evaluated and the results of Tensile Strength, Elongation at break, and Young's modulus were shown in Fig. 4. As it turns out, some specimens are tough and some are brittle. The highest tensile strength is related to Run-5 and the lowest value is related to Run-4 and Run-13. In addition, the highest elongation at break was related to Run-1 and Run-13, while the lowest value was related to Run-3, Run-4, Run-5, Run-10 and Run20. Also, the highest Young's modulus belonged to Run-5, Run-10 and Run-18, while the lowest 
belonged to Run-1, Run-9, Run-13 and Run-16. A prepared film will have better mechanical properties that have appropriate both elongation at break and tensile strength [33]. Sen and Das reported 4.5 to $16.96 \mathrm{MPa}$ for the tensile strength of films based on starch, PVA and glycerol [34]. In another study, this range is between 0.4 and $4.4 \mathrm{MPa}$ compared to films made from amaranth flour with glycerol and sorbitol [35].

Fig. 4.

Three dimensional response surface plots of tensile strength were shown in Fig. 5. As shown in Fig. 5 (A and B), the amount of PVA had a dual behavior on tensile strength. Increasing its value first reduces and then increases the tensile strength. The reason is the change in the amount of load-bearing component in the alloy. When the amount of PVA is low, starch is the load-bearing component. Therefore, increasing the amount of PVA, which is in other words reduces the amount of starch, reduces the tensile strength. But this trend has risen from an optimal value for PVA, which is about $0.6 \mathrm{~g}$. But the effect of glycerol on the tensile strength of the prepared films was completely opposite to the behavior of the PVA. This means that it first had an upward trend and then a downward trend. Glycerol has three groups of hydroxyl in its structure, which strongly enhances the hydrogen interactions between the starch and PVA chains. Therefore, glycerol initially plays a compatible role and strengthens the alloy interface. But by increasing more than $1 \mathrm{~g}$ in the alloy, it has reduced the mechanical strength. However, glycerol is a small molecule, and an excessive increase in its amount has reduced the mechanical properties of the alloy. Here glycerol has a plasticizing role.

Fig. 5.

\subsection{Effect on Elongation at Break}

Three dimensional response surface plots of elongation at break were shown in Fig. 5(D-F). The results show that the amount of glycerol and PVA is directly related to elongation. However, glycerol is more effective than PVA. Run-5 is brittle and its elongation is less than $10 \%$ because there is no amount of PVA in this sample. Run-4 has the same condition because its glycerol content is the lowest. Fig. 4 showed that specimens 3, 4, 10, and 20 had a slight elongation and were brittle. According to Table 1, it is clear that the amount of glycerol and PVA in these samples was low. The zinc oxide nanoparticles have a reducing effect on elongation although not 
very noticeable (Fig. 5F). Sen and Das showed that the elongation value of starch/PVA/glutaraldehyde based films was in the range of $1.75-16.92 \%$ [34].

\section{4. $\quad$ Effect on Water Vapor Permeability (WVP)}

Permeability is an important criterion in food preservation. The freshness of food and fruits as well as their rate of spoilage depends on the amount of water vapor as well as the oxygen passing through the packing membranes. The prepared films were analyzed by WVP test which results are shown in Fig. 6(A) in the form of bar graphs. Therefore, this evaluation was not performed on the samples that did not form a suitable film and its value was not considered in the experimental design. 3D graphs shown in Fig. 6(B-D) confirmed that the amount of PVA and glycerol have a synergistic effect on the amount of the WVP. But the effect of nanoparticles of $\mathrm{ZnO}$ on WVP has a maximum point which occurred at about $1.5 \%$. After this amount, with increasing the amount of nanoparticles, their barrier property has increased and water vapor permeability has been prevented. According to Table 1, the value of WVP was for all Runs from 0 to $6.77 \times 10^{-8} \mathrm{gm}^{-1} \mathrm{~s}^{-1} \mathrm{~Pa}^{-1}$. In a study on cellulose/PVA/glycerol-based films, Cazon et al. Reported amount of WVP about $5.8 \times 10^{-9}$ (g/m.s.pa) [36]. Sen and Das examined films of starch/PVA/glutaraldehyde and found that the WVP was around 0.80-0.160 (g.mm/m².kPa.h) [37]. Cano et al. found that the WVP of starch/PVA films increased with increasing starch content, which is due to the different densities between starch and PVA [38].

\section{Fig. 6.}

\subsection{Solubility of Starch/PVA/ZnO nanocomposite film}

Since both starch and PVA are hydrophilic and water soluble, evaluating the solubility of the films produced from them is an important criterion. The solubility results of the prepared nanocomposite films are shown in Fig. 7(A) which have between 18.2 to $52.38 \%$ solubility. In another similar study, Soon-Do Yoon et al. recorded a solubility value of 12.6-59.2 [39]. To better understand the effect of variable parameters on the solubility, the results of the experimental design are shown by three dimensions in Fig. 7(B-D). Increasing the amount of PVA and glycerol synergistically has increased the water solubility of films. Because glycerol and PVA are hydrophilic, they easily absorb water into the film structure, causing more dissolution of the films. The effect of $\mathrm{ZnO}$ on solubility was first increasing and then decreasing. However, these changes are not very noticeable. Of course, packaging films are seldom 
completely immersed in water for 24 hours. Solubility and water absorption are important because if the samples have more water absorption and solubility, they will have better degradability and biocompatibility.

Fig. 7.

\subsection{Swelling of Starch/PVA/ZnO nanocomposite films}

The swelling value of each of the samples is shown in Fig. 8(A) as a bar graph. The swelling ratio of the samples is approximately less than 100\%, except for Run-5 and Run-20. 3D charts show a better analysis of the effect of different variables on swelling ratio. All diagrams in Fig. 8(B-D) show that none of the parameters had a significant effect on swelling, except for the amount of PVA and glycerol, which had a synergistic effect in very large quantities. In a similar study, Yan Qin et al. estimated film swelling rates between 171.1-212.93\% [40]. Also, Soon-Do Yoon et al. in another study calculated the water uptake between 101.7-2999.4\% [39].

\section{Fig. 8.}

\subsection{Statistical analysis}

The quadratic relationship models between the parameters affecting each of the test design responses are given in Table S2. The data presented in Table S2 show that all models were significant at the 5\% confidence level; since P-values were less than 0.05. Lack of Fit (LOF) represents the variety of data around the fitted model, and if the model does not fit properly with the data, this will be significant [23]. In other words, this statistical measurement shows how close the data is to the regression line. The high $\mathrm{R}^{2}$ coefficient ensures a satisfactory adjustment of the quadratic model with the experimental data. Also, a high value of $\mathrm{R}^{2}$, close to 1 , is desirable, and reasonable agreement with the regulated $R^{2}$ is necessary [41]. Therefore, according to the report $\mathrm{R}^{2}$ and adj- $\mathrm{R}^{2}$ (Table $\mathrm{S} 2$ ), it can be concluded that the quadratic model adequately predicts the relationship between parameters of the process and related responses. Adequate precision (AP) compares the range of predicted values at design points with the average prediction error, and ratios greater than 4 indicate discrimination of the appropriate model [41]. As Table S2 shows, AP values above 4 for all responses confirm that all predicted models can be used to navigate the design space defined by the CCD. In this regard, the predicted graphs versus real values (Fig. S1) can be useful for further evaluation of model 
satisfaction. As can be seen, there is good agreement between the actual data and the data obtained from the models. The governing relationships between the process parameters and the selected responses are presented in Table S2, and the graphs of the response levels are shown graphically in Fig. S1.

\subsection{Optimization and validation}

All films produced may not be used as packaging films. Therefore, optimization using RSM software can provide us with the best candidates. Hence films with high film formation, maximum tensile strength, and high elongation, minimum solubility, permeability, and swelling are considered. The desirability plot was obtained in Fig. S2 with optimized conditions to show all responses including the optimal conditions for preparation suitable films. Accordingly, the optimal sample was prepared and is shown in Fig. 9(A). The optimal values for each of the parameters are: PVA: 0.9 (g) -Starch: 3.1 (g) -Glycerol: 0.75 (g) -ZnO: 1.25\%. Also, the predicted responses for the formation 0.924 (a. u.) tensile strength $9.85 \mathrm{Mpa}$, elongation $22.538 \%$, solubility $38.365 \%$, water vapor permeability $4.11 \times 10-5 \%$, swelling $69.728 \%$ were determined. SEM Images from cross section of optimal sample at (Fig. 9C, D) two different magnifications show that there are no aggregations of nanoparticles on the sample. A validation experiment was performed using optimal conditions three times, and the average values obtained from the formation, tensile strength, elongation, solubility, water vapor permeability, and swelling has an error of less than $9 \%$ compared to predictions. Therefore, there is a significant arrangement between the experimental values and the predicted values based on the model.

\section{Table 2.}

Fig. 9.

\section{Conclusions}

In this study, starch/PVA/ZnO nanocomposite films were evaluated and optimized by RSM. For this purpose, the amount of starch, PVA, glycerol and zinc oxide were considered as variables affecting the final properties of the films in the experimental design. Film formation, mechanical properties, swelling, solubility, and water vapor permeability (WVP) were selected as responses of RSM. Results shown with increasing the amount of PVA, the film formation of the samples has increased. The highest tensile strength is related to Run-5 and the lowest value is related to 
Run-4 and Run-13. In addition, the highest elongation at break was related to Run-1 and Run-13, while the lowest value was related to Run-3, Run-4, Run-5, Run-10 and Run-20. The amount of PVA had a dual behavior on tensile strength. Increasing its value first reduces and then increases the tensile strength. The reason is the change in the amount of load-bearing component in the alloy. When the amount of PVA is low, starch is the load-bearing component. Glycerol did the opposite because it acts as a plasticizer. Results confirmed that the amount of PVA and glycerol have a synergistic effect on the amount of the WVP. But the effect of nanoparticles of $\mathrm{ZnO}$ on WVP has a maximum point which occurred at about $1.5 \%$. After this amount, with increasing the amount of nanoparticles, their barrier property has increased and water vapor permeability has been prevented. The value of WVP was for all Runs from 0 to $6.77 \times 10^{-8} \mathrm{gm}^{-1} \mathrm{~s}^{-1} \mathrm{~Pa}^{-1}$. The optimal values for each of the parameters with desirability of about $50 \%$ are: PVA: $0.9(\mathrm{~g})$ Starch: 3.1 (g) -Glycerol: 0.75 (g) - $\mathrm{ZnO}: 1.25 \%$. The amounts of actual and predicted responses were well matched.

\section{Declarations}

Funding: This research did not receive any specifc grant from funding agencies in the public, commercial, or not-for-proft sectors.

Conflict of interest: The authors declare that there is no conflict of interest associated with this manuscript.

\section{References}

[1] M. Avella, J.J. De Vlieger, M.E. Errico, S. Fischer, P. Vacca, M.G. Volpe, Biodegradable starch/clay nanocomposite films for food packaging applications, Food chemistry 93(3) (2005) 467-474.

[2] Q.K. Beg, V. Sahai, R. Gupta, Statistical media optimization and alkaline protease production from Bacillus mojavensis in a bioreactor, Process Biochemistry 39(2) (2003) 203-209.

[3] D. Piñeros-Hernandez, C. Medina-Jaramillo, A. López-Córdoba, S. Goyanes, Edible cassava starch films carrying rosemary antioxidant extracts for potential use as active food packaging, Food hydrocolloids 63 (2017) 488-495.

[4] S.A. Attaran, A. Hassan, M.U. Wahit, Materials for food packaging applications based on bio-based polymer nanocomposites: A review, Journal of Thermoplastic Composite Materials 30(2) (2017) 143-173.

[5] S.M. Keshk, A.A. El-Zahhar, M.A. Haija, S. Bondock, Synthesis of a magnetic nanoparticles/dialdehyde starch-based composite film for food packaging, Starch-Stärke 71(1-2) (2019) 1800035. 
[6] O. Ochoa-Yepes, C. Medina-Jaramillo, L. Guz, L. Famá, Biodegradable and edible starch composites with fiber-rich lentil flour to use as food packaging, Starch-Stärke 70(7-8) (2018) 1700222. ( $\varepsilon$-caprolactone) nanocomposites by cellulose nanowhiskers, Polymer Composites 41(2) (2020) 624-632.

[8] F. Versino, O.V. Lopez, M.A. Garcia, N.E. Zaritzky, Starch-based films and food coatings: An overview, Starch-Stärke 68(11-12) (2016) 1026-1037.

[9] F.M. Pelissari, D.C. Ferreira, L.B. Louzada, F. dos Santos, A.C. Corrêa, F.K.V. Moreira, L.H. Mattoso, Starch-based edible films and coatings: An eco-friendly alternative for food packaging, Starches for Food Application, Elsevier2019, pp. 359-420.

[10] S. Mathew, S. Snigdha, J. Mathew, E. Radhakrishnan, Poly (vinyl alcohol): montmorillonite: boiled rice water (starch) blend film reinforced with silver nanoparticles; characterization and antibacterial properties, Applied Clay Science 161 (2018) 464-473. [11] A. Nazrin, S. Sapuan, R. Ilyas, Thermoplastic starch blended poly (lactic) acid for food packaging application: Mechanical properties, 6th Postgraduate Seminar on Natural Fiber Reinforced Polymer Composites, 2018, pp. 79-84. citrate/polyethylene glycol on plasticization and retrogradation of maize starch, International journal of biological macromolecules 154 (2020) 1471-1477. [13] W.S. Lyoo, W.S. Ha, Structure and properties of microfibrillar poly (vinyl alcohol) fibres prepared by saponification under shearing force of poly (vinyl pivalate), Polymer 37(14) (1996) 3121-3129.

[14] F. Shakerardakani, X.-H. Li, X.-X. Ling, J. Li, G.-Q. Tang, Y. Liu, B. Monfaredi, Evidence for Archean crust in Iran provided by ca $2.7 \mathrm{Ga}$ zircon xenocrysts within amphibolites from the Sanandaj-Sirjan zone, Zagros orogen, Precambrian Research 332 (2019) 105390.

[15] X. Tang, S. Alavi, Recent advances in starch, polyvinyl alcohol based polymer blends, nanocomposites and their biodegradability, Carbohydrate polymers 85(1) (2011) 7-16.

[16] P. Ghaffari-Bohlouli, F. Hamidzadeh, P. Zahedi, M. Shahrousvand, M. Fallah-Darrehchi, Antibacterial nanofibers based on poly (l-lactide-co-d, l-lactide) and poly (vinyl alcohol) used in wound dressings potentially: A comparison between hybrid and blend properties, Journal of Biomaterials Science, Polymer Edition 31(2) (2020) 219-243.

[17] T. Min, Z. Zhu, X. Sun, Z. Yuan, J. Zha, Y. Wen, Highly efficient antifogging and antibacterial food packaging film fabricated by novel quaternary ammonium chitosan composite, Food chemistry 308 (2020) 125682.

[18] I. Kim, K. Viswanathan, G. Kasi, S. Thanakkasaranee, K. Sadeghi, J. Seo, ZnO Nanostructures in Active Antibacterial Food Packaging: Preparation Methods, Antimicrobial Mechanisms, Safety Issues, Future Prospects, and Challenges, Food Reviews International (2020) 1-29.

[19] N. Vigneshwaran, S. Kumar, A. Kathe, P. Varadarajan, V. Prasad, Functional finishing of cotton fabrics using zinc oxide-soluble starch nanocomposites, Nanotechnology 17(20) (2006) 5087.

[20] L.h. Wang, D.Q. Li, Y. Fu, H.P. Wang, J.F. Zhang, Z.F. Yuan, R.X. Sun, R. Zeng, S.M. He, W. Gao, pFind 2.0: a software package for peptide and protein identification via tandem mass spectrometry, Rapid Communications in Mass Spectrometry: An International Journal Devoted 
to the Rapid Dissemination of Up-to-the-Minute Research in Mass Spectrometry 21(18) (2007) 2985-2991. [21] Y.-J. Lee, D.S. Ruby, D.W. Peters, B.B. McKenzie, J.W. Hsu, ZnO nanostructures as efficient antireflection layers in solar cells, Nano letters 8(5) (2008) 1501-1505.

[22] D.S. Vicentini, A. Smania Jr, M.C. Laranjeira, Chitosan/poly (vinyl alcohol) films containing $\mathrm{ZnO}$ nanoparticles and plasticizers, Materials Science and Engineering: C 30(4) (2010) 503-508.

[23] S. Ghafari, H.A. Aziz, M.H. Isa, A.A. Zinatizadeh, Application of response surface methodology (RSM) to optimize coagulation-flocculation treatment of leachate using polyaluminum chloride (PAC) and alum, Journal of hazardous materials 163(2-3) (2009) 650-656. [24] C. Medina-Jaramillo, O. Ochoa-Yepes, C. Bernal, L. Famá, Active and smart biodegradable packaging based on starch and natural extracts, Carbohydrate Polymers 176 (2017) 187-194.

[25] M. Hajikhani, M.M. Khanghahi, M. Shahrousvand, J. Mohammadi-Rovshandeh, A. Babaei, S.M.H. Khademi, Intelligent superabsorbents based on a xanthan gum/poly (acrylic acid) semiinterpenetrating polymer network for application in drug delivery systems, International journal of biological macromolecules 139 (2019) 509-520.

[26] S.M. Hosseini, M. Shahrousvand, S. Shojaei, H.A. Khonakdar, A. Asefnejad, V. Goodarzi, Preparation of superabsorbent eco-friendly semi-interpenetrating network based on cross-linked poly acrylic acid/xanthan gum/graphene oxide (PAA/XG/GO): Characterization and dye removal ability, International Journal of Biological Macromolecules 152 (2020) 884-893.

[27] C.A. Romero-Bastida, L.A. Bello-Pérez, M.A. García, M.N. Martino, J. Solorza-Feria, N.E. Zaritzky, Physicochemical and microstructural characterization of films prepared by thermal and cold gelatinization from non-conventional sources of starches, Carbohydrate Polymers 60(2) (2005) 235-244.

[28] L. Famá, P.G. Rojo, C. Bernal, S. Goyanes, Biodegradable starch based nanocomposites with low water vapor permeability and high storage modulus, Carbohydrate polymers 87(3) (2012) 1989-1993.

[29] S. Pourbashir, M. Shahrousvand, M. Ghaffari, Preparation and characterization of semiIPNs of polycaprolactone/poly (acrylic acid)/cellulosic nanowhisker as artificial articular cartilage, International journal of biological macromolecules 142 (2020) 298-310.

[30] M. Shahrousvand, M. Ghollasi, A.A.K. Zarchi, A. Salimi, Osteogenic differentiation of hMSCs on semi-interpenetrating polymer networks of polyurethane/poly (2-hydroxyethyl methacrylate)/cellulose nanowhisker scaffolds, International journal of biological macromolecules 138 (2019) 262-271.

[31] X. Luo, J. Li, X. Lin, Effect of gelatinization and additives on morphology and thermal behavior of corn starch/PVA blend films, Carbohydrate Polymers 90(4) (2012) 1595-1600. [32] H. Tian, J. Yan, A.V. Rajulu, A. Xiang, X. Luo, Fabrication and properties of polyvinyl alcohol/starch blend films: Effect of composition and humidity, International journal of biological macromolecules 96 (2017) 518-523.

[33] M. Shahrousvand, M.S. Hoseinian, M. Ghollasi, A. Karbalaeimahdi, A. Salimi, F.A. Tabar, Flexible magnetic polyurethane/Fe2O3 nanoparticles as organic-inorganic nanocomposites for biomedical applications: properties and cell behavior, Materials Science and Engineering: C 74 (2017) 556-567.

[34] C. Sen, M. Das, Biodegradability of starch based self-supporting antimicrobial film and its effect on soil quality, Journal of Polymers and the Environment 26(12) (2018) 4331-4337. 
467 [35] D. Tapia-Blácido, P. do Amaral Sobral, F. Menegalli, Optimization of amaranth flour films 468 plasticized with glycerol and sorbitol by multi-response analysis, LWT-Food Science and 469 Technology 44(8) (2011) 1731-1738.

470 [36] P. Cazón, G. Velázquez, M. Vázquez, Regenerated cellulose films combined with glycerol 471 and polyvinyl alcohol: Effect of moisture content on the physical properties, Food Hydrocolloids 472103 (2020) 105657.

473 [37] C. Sen, M. Das, Self-supporting-film from starch, poly (vinyl alcohol), and glutaraldehyde: 474 Optimization of composition using response surface methodology, Journal of Applied Polymer 475 Science 134(6) (2017).

476 [38] A. Cano, E. Fortunati, M. Cháfer, C. González-Martínez, A. Chiralt, J. Kenny, Effect of 477 cellulose nanocrystals on the properties of pea starch-poly (vinyl alcohol) blend films, Journal of 478 materials science 50(21) (2015) 6979-6992.

479 [39] S.-D. Yoon, M.-H. Park, H.-S. Byun, Mechanical and water barrier properties of 480 starch/PVA composite films by adding nano-sized poly (methyl methacrylate-co-acrylamide) 481 particles, Carbohydrate Polymers 87(1) (2012) 676-686.

482 [40] Y. Qin, F. Xu, L. Yuan, H. Hu, X. Yao, J. Liu, Comparison of the physical and functional 483 properties of starch/polyvinyl alcohol films containing anthocyanins and/or betacyanins, 484 International Journal of Biological Macromolecules 163 (2020) 898-909.

485 [41] M.Y. Noordin, V. Venkatesh, S. Sharif, S. Elting, A. Abdullah, Application of response 486 surface methodology in describing the performance of coated carbide tools when turning AISI 4871045 steel, Journal of materials processing technology 145(1) (2004) 46-58. 


\section{Figure legends}

500 Fig. 1. SEM images of $\mathrm{ZnO}$ nanoparticles in two magnifications.

501 Fig. 2. Images of the appearance of prepared films based on experimental design in different 502 amounts of starch, PVA, glycerol and nanoparticles of $\mathrm{ZnO}$.

503 Fig. 3. Three dimensional response surface plots of film formation in the face of change in: (A) 504 Amount of glycerol and PVA; (B) Amount of $\mathrm{ZnO}$ and PVA; (C) Amount of $\mathrm{ZnO}$ and glycerol.

505 506
Fig. 4. Diagrams of mechanical properties of prepared films: (A) Tensile-Strain diagram; (B) Tensile strength; (C) Elongation at break; (D) Young's modulus.

Fig. 5. Three dimensional response surface plots of tensile strength and elongation at break in the face of change in: (A and D) Amount of glycerol and PVA; (B and E) Amount of ZnO and PVA; (C and F) Amount of $\mathrm{ZnO}$ and glycerol.

Fig. 6. Three dimensional response surface plots of water vapor permeability (WVP) in the face of change in: (A) Amount of glycerol and PVA; (B) Amount of $\mathrm{ZnO}$ and PVA; (C) Amount of $\mathrm{ZnO}$ and glycerol.

Fig. 7. (A) Water solubility of starch/PVA/ZnO nanocomposite films; Three dimensional response surface plots of water solubility in the face of change in: (B) Amount of glycerol and PVA; (C) Amount of $\mathrm{ZnO}$ and PVA; (D) Amount of $\mathrm{ZnO}$ and glycerol.

Fig. 8. (A) Swelling of starch/PVA/ZnO nanocomposite films; Three dimensional response surface plots of swelling in the face of change in: (B) Amount of glycerol and PVA; (C) Amount of $\mathrm{ZnO}$ and PVA; (D) Amount of $\mathrm{ZnO}$ and glycerol.

Fig. 9. (A) Prepared optimal film; (B) FTIR analysis of prepared optimal film and raw materials; (C) and (D) SEM images from cross-section of the optimal film in two magnifications. 
524 Table 1 Experimental design parameters and responses

\begin{tabular}{|c|c|c|c|c|c|c|c|c|c|c|c|c|c|c|c|c|}
\hline \multirow[t]{2}{*}{ Std } & \multirow[t]{2}{*}{ Run } & \multirow[t]{2}{*}{$\begin{array}{c}\text { PVA } \\
(\text { g) }\end{array}$} & \multirow[t]{2}{*}{$\begin{array}{l}\text { Glycerol } \\
\text { (g) }\end{array}$} & \multirow[t]{2}{*}{$\begin{array}{l}\mathrm{ZnO} \\
(\%)\end{array}$} & \multicolumn{2}{|c|}{$\begin{array}{l}\text { Formation } \\
\text { (a. u.) }\end{array}$} & \multicolumn{2}{|c|}{$\begin{array}{c}\text { Tensile Strength } \\
\text { (MPa) }\end{array}$} & \multicolumn{2}{|c|}{$\begin{array}{c}\text { Elongation } \\
(\%)\end{array}$} & \multicolumn{2}{|c|}{$\begin{array}{c}\text { Solubility } \\
(\%)\end{array}$} & \multicolumn{2}{|c|}{$\begin{array}{c}\text { Permeability } \\
\text { (gH } \mathrm{gH}_{2} \text { O/Pa.s.m) }\end{array}$} & \multicolumn{2}{|c|}{$\begin{array}{c}\text { Swelling } \\
(\%)\end{array}$} \\
\hline & & & & & Predicted & Actual & Predicted & Actual & Predicted & Actual & Predicted & Actual & Predicted & Actual & Predicted & Actual \\
\hline 4 & 1 & 0.9 & 1.25 & 1.25 & 0.7980 & 0.9 & 6.26 & 6.8 & 82.33 & 78.33 & 46.33 & 50 & $\begin{array}{l}4.609 \mathrm{E}- \\
08\end{array}$ & $\begin{array}{c}4.636 \mathrm{E}- \\
08\end{array}$ & 49.76 & 61.90 \\
\hline 20 & 2 & 0.6 & 1 & 2.5 & 0.2080 & 0.1 & 7.94 & 8 & 33.27 & 35 & 25.40 & 35.71 & $\begin{array}{c}4.193 \mathrm{E}- \\
08\end{array}$ & $\begin{array}{c}4.272 \mathrm{E}- \\
08\end{array}$ & 47.76 & 52.63 \\
\hline 6 & 3 & 0.9 & 0.75 & 3.75 & 0.5230 & 0.6 & 5.82 & 6.13 & 15.48 & 10 & 29.42 & 30.76 & $\begin{array}{c}1.167 \mathrm{E}- \\
08\end{array}$ & $\begin{array}{c}2.056 \mathrm{E}- \\
08\end{array}$ & 61.46 & 73.68 \\
\hline 11 & 4 & 0.6 & 0.5 & 2.5 & 0.5801 & 0.5 & 2.98 & 2.58 & -3.54 & 0.5 & 26.02 & 25.71 & $\begin{array}{c}5.395 \mathrm{E}- \\
09\end{array}$ & 0.0000 & 132.56 & 120 \\
\hline 9 & 5 & 0 & 1 & 2.5 & 0.1551 & 0.1 & 13.49 & 14.1 & 7.30 & 7.476 & 19.75 & 18.18 & $\begin{array}{c}-2.643 \mathrm{E}- \\
09\end{array}$ & 0.0000 & 205.39 & 218.7 \\
\hline 15 & 6 & 0.6 & 1 & 2.5 & 0.2080 & 0.3 & 7.94 & 7.94 & 33.27 & 35 & 25.40 & 22.72 & $\begin{array}{c}4.193 \mathrm{E}- \\
08\end{array}$ & $\begin{array}{c}4.172 \mathrm{E}- \\
08\end{array}$ & 47.76 & 46.66 \\
\hline 19 & 7 & 0.6 & 1 & 2.5 & 0.2080 & 0.1 & 7.94 & 7.94 & 33.27 & 35 & 25.40 & 22.72 & $\begin{array}{c}4.193 \mathrm{E}- \\
08\end{array}$ & $\begin{array}{c}4.122 \mathrm{E}- \\
08\end{array}$ & 47.76 & 46.66 \\
\hline 16 & 8 & 0.6 & 1 & 2.5 & 0.2080 & 0.1 & 7.94 & 7.94 & 33.27 & 35 & 25.40 & 22.72 & $\begin{array}{l}4.193 \mathrm{E}- \\
08\end{array}$ & $\begin{array}{c}4.352 \mathrm{E}- \\
08\end{array}$ & 47.76 & 46.66 \\
\hline 7 & 9 & 0.3 & 1.25 & 3.75 & 0.5480 & 0.6 & 8.99 & 8.3 & 49.11 & 47.5 & 29.75 & 32.35 & $\begin{array}{l}3.971 \mathrm{E}- \\
08\end{array}$ & $\begin{array}{c}4.056 \mathrm{E}- \\
08\end{array}$ & 78.70 & 65 \\
\hline 5 & 10 & 0.3 & 0.75 & 3.75 & 0.3543 & 0.4 & 6.22 & 5.6 & 8.07 & 1.666 & 21.94 & 21.39 & $\begin{array}{c}-4.533 \mathrm{E}- \\
10\end{array}$ & 0.0000 & 104.42 & 92.85 \\
\hline 13 & 11 & 0.6 & 1 & 0 & 0.4551 & 0.35 & 8.85 & 8.23 & 52.91 & 55.46 & 32.64 & 30 & $\begin{array}{l}-3.222 \mathrm{E}- \\
09\end{array}$ & 0.0000 & 102.48 & 90 \\
\hline 17 & 12 & 0.6 & 1 & 2.5 & 0.2080 & 0.25 & 7.94 & 7.94 & 33.27 & 35 & 25.40 & 22.72 & $\begin{array}{c}4.193 \mathrm{E}- \\
08\end{array}$ & $\begin{array}{c}4.072 \mathrm{E}- \\
08\end{array}$ & 47.76 & 46.66 \\
\hline 12 & 13 & 0.6 & 1.5 & 2.5 & 0.6676 & 0.6 & 2.63 & 3.1 & 94.05 & 100.4 & 41.80 & 39 & $\begin{array}{l}5.559 \mathrm{E}- \\
08\end{array}$ & $\begin{array}{c}6.026 \mathrm{E}- \\
08\end{array}$ & 78.01 & 90 \\
\hline 14 & 14 & 0.6 & 1 & 5 & 0.5926 & 0.55 & 6.00 & 6.7 & 37.62 & 45.46 & 33.80 & 33.33 & $\begin{array}{l}3.947 \mathrm{E}- \\
09\end{array}$ & 0.0000 & 58.10 & 70 \\
\hline 3 & 15 & 0.3 & 1.25 & 1.25 & 0.0293 & 0.1 & 8.28 & 7.89 & 54.09 & 49.16 & 19.64 & 21.42 & $\begin{array}{l}8.164 \mathrm{E}- \\
09\end{array}$ & 0.0000 & 105.94 & 94.28 \\
\hline 8 & 16 & 0.9 & 1.25 & 3.75 & 0.6918 & 0.75 & 6.58 & 6.1 & 60.95 & 48.35 & 49.43 & 50.1 & $\begin{array}{c}5.141 \mathrm{E}- \\
08\end{array}$ & $\begin{array}{c}4.983 \mathrm{E}- \\
08\end{array}$ & 100.19 & 90 \\
\hline 18 & 17 & 0.6 & 1 & 2.5 & 0.2080 & 0.25 & 7.94 & 7.94 & 33.27 & 35 & 25.40 & 22.72 & $\begin{array}{l}4.193 \mathrm{E}- \\
08\end{array}$ & $\begin{array}{c}4.097 \mathrm{E}- \\
08\end{array}$ & 47.76 & 46.66 \\
\hline 2 & 18 & 0.9 & 0.75 & 1.25 & 0.9043 & 1 & 9.39 & 10 & 25.79 & 17 & 38.36 & 38.88 & $\begin{array}{c}3.605 \mathrm{E}- \\
08\end{array}$ & $\begin{array}{c}3.593 \mathrm{E}- \\
08\end{array}$ & 78.59 & 92.85 \\
\hline 10 & 19 & 1.2 & 1 & 2.5 & 1.09 & 1 & 11.08 & 10.55 & 42.95 & 53.18 & 53.92 & 52.38 & $\begin{array}{c}4.741 \mathrm{E}- \\
08\end{array}$ & $\begin{array}{c}4.404 \mathrm{E}- \\
08\end{array}$ & 106.24 & 92.31 \\
\hline 1 & 20 & 0.3 & 0.75 & 1.25 & 0.1105 & 0.2 & 9.38 & 9.778 & 1.98 & 4.18 & 23.87 & 26.31 & $\begin{array}{c}-2.299 \mathrm{E}- \\
09\end{array}$ & 0.0000 & 199.23 & 210 \\
\hline
\end{tabular}

525

526 Table 2. Actual and predicted values of responses for prepared optimal film.

\begin{tabular}{lllllll}
\hline & $\begin{array}{c}\text { Formation } \\
\text { (a. u.) }\end{array}$ & $\begin{array}{c}\text { Tensile Strength } \\
\text { (Mpa) }\end{array}$ & $\begin{array}{c}\text { Elongation } \\
(\boldsymbol{\%})\end{array}$ & $\begin{array}{l}\text { Water Vapor } \\
\text { Permeability } \\
\left(\mathbf{g H}_{2} \mathbf{O} / \text { Pa.s.m) }\right.\end{array}$ & $\begin{array}{c}\text { Solubility } \\
(\boldsymbol{\%})\end{array}$ & $\begin{array}{c}\text { Swelling } \\
(\boldsymbol{\%})\end{array}$ \\
\hline Predicted & 0.924 & 9.38 & 22.53 & $4.11 \times 10^{-8}$ & 38.36 & 69.72 \\
\hline Actual & 0.9 & 10.9 & 21.3 & $5.8 \times 10^{-8}$ & 35 & 95.88 \\
\hline
\end{tabular}

527

528 

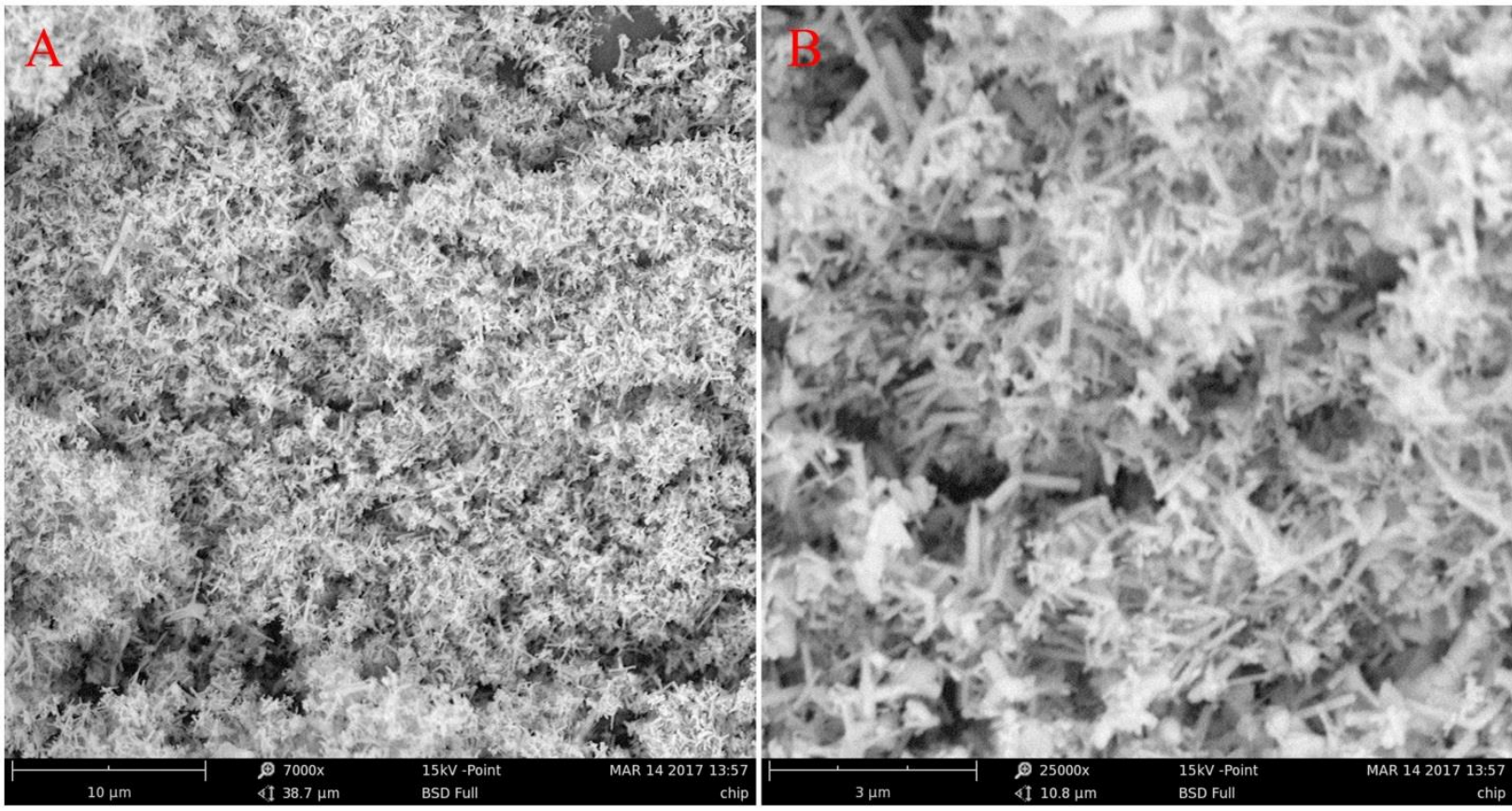

532

Fig. 1.

533

534

535

536

537

538

539

540

541

542 


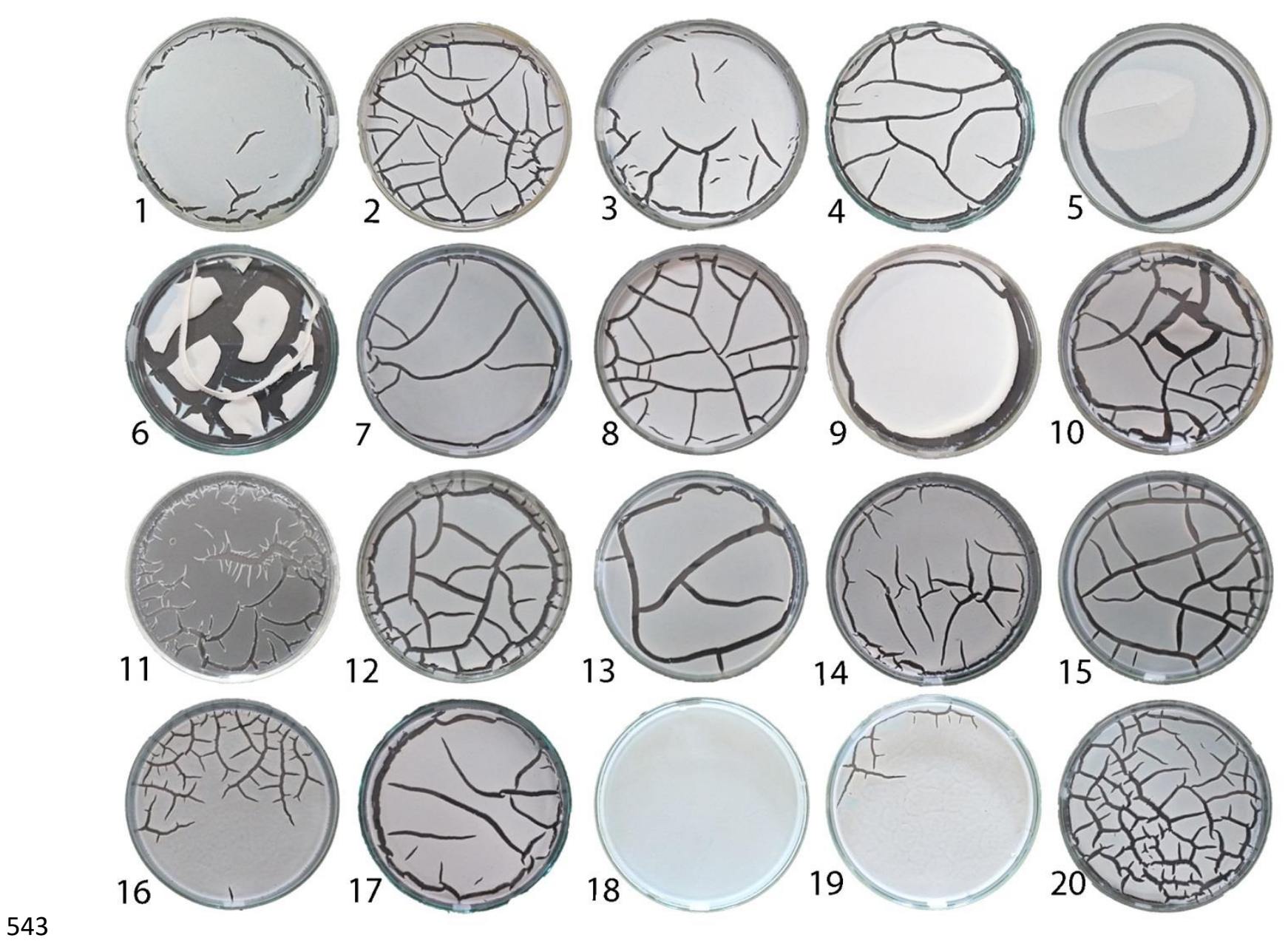

544

Fig. 2.

545

546

547

548

549

550

551 


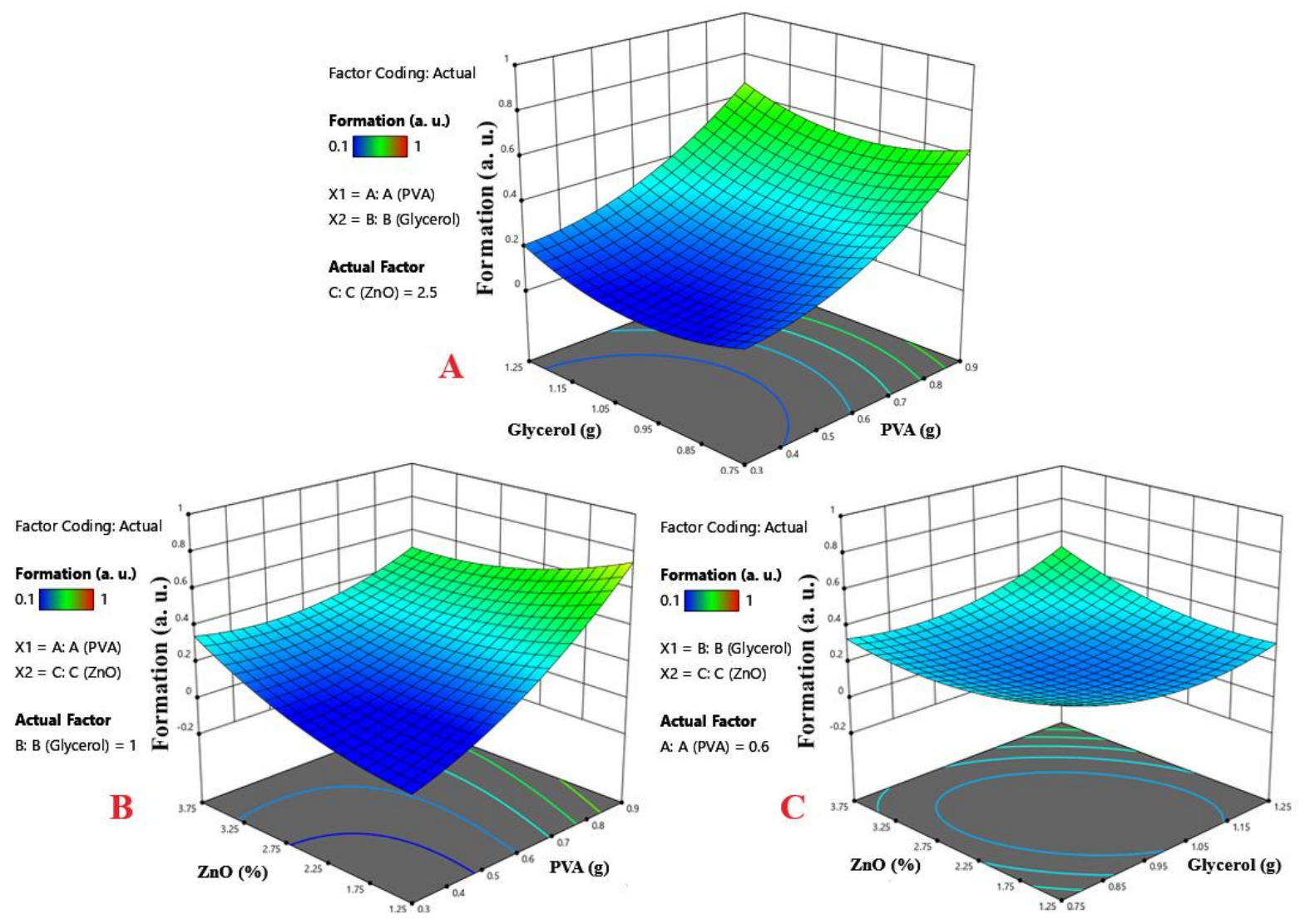




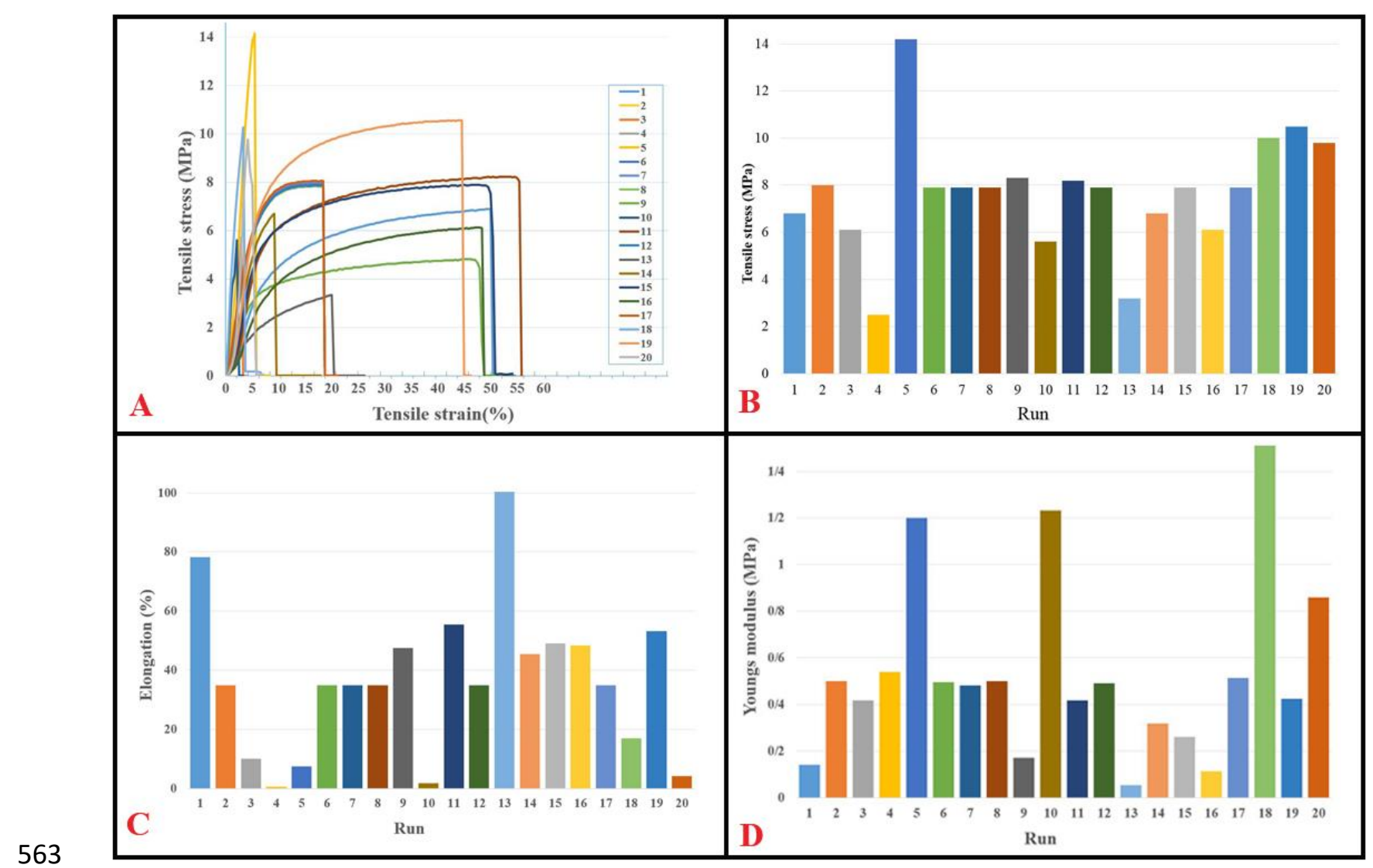

564

Fig. 4.

565

566

567

568

569

570

571

572

573 

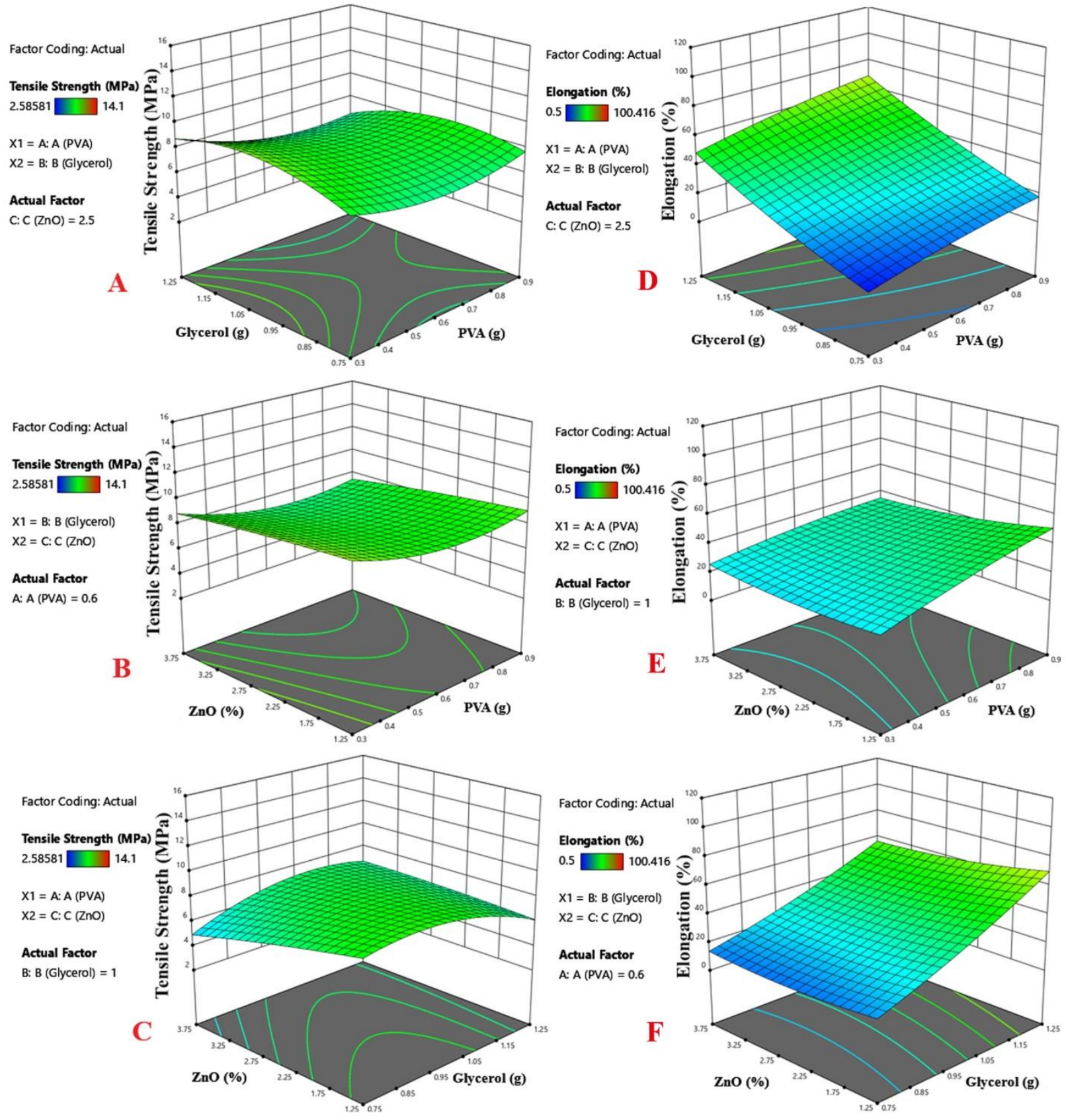


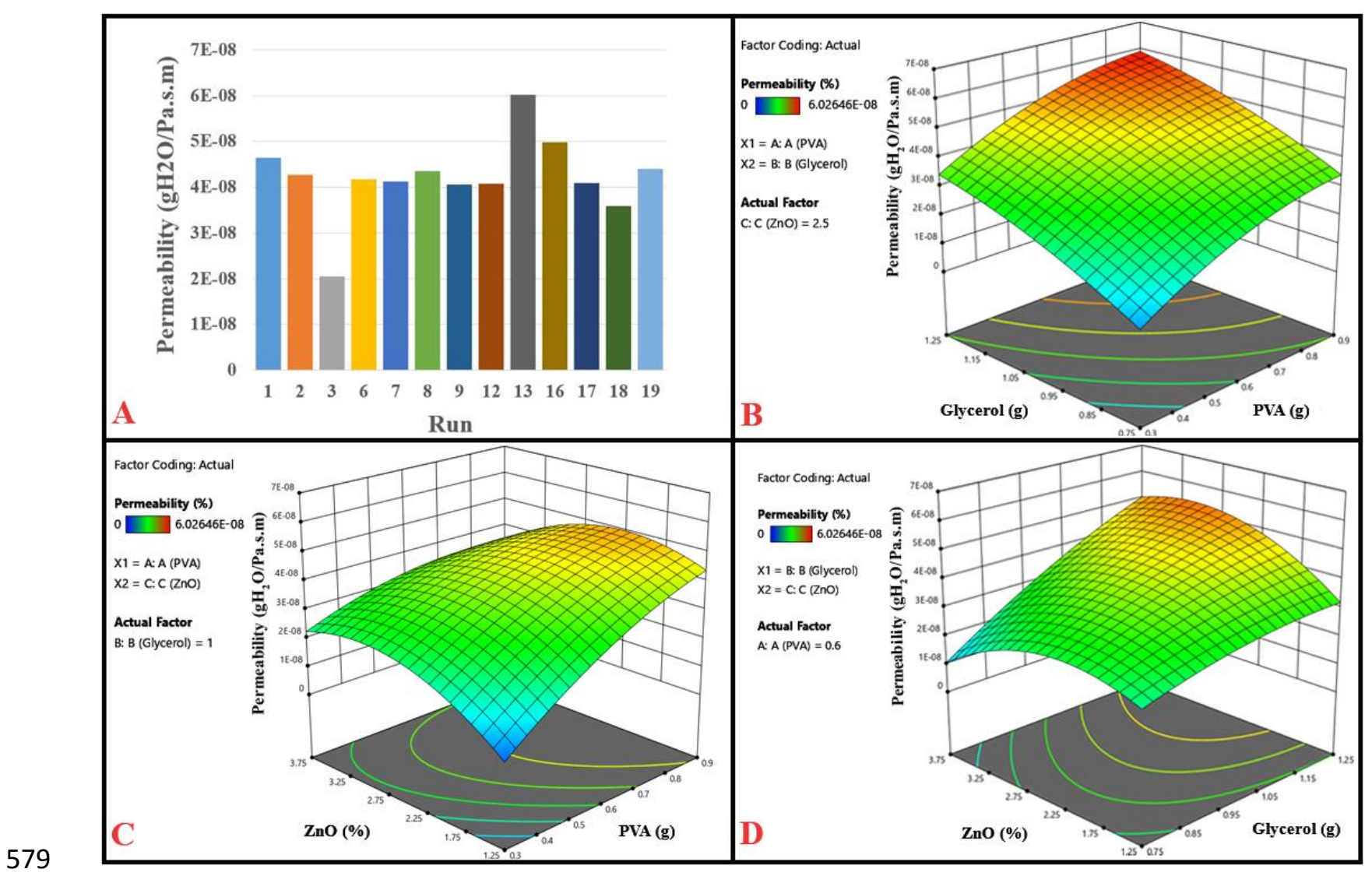

Fig. 6. 


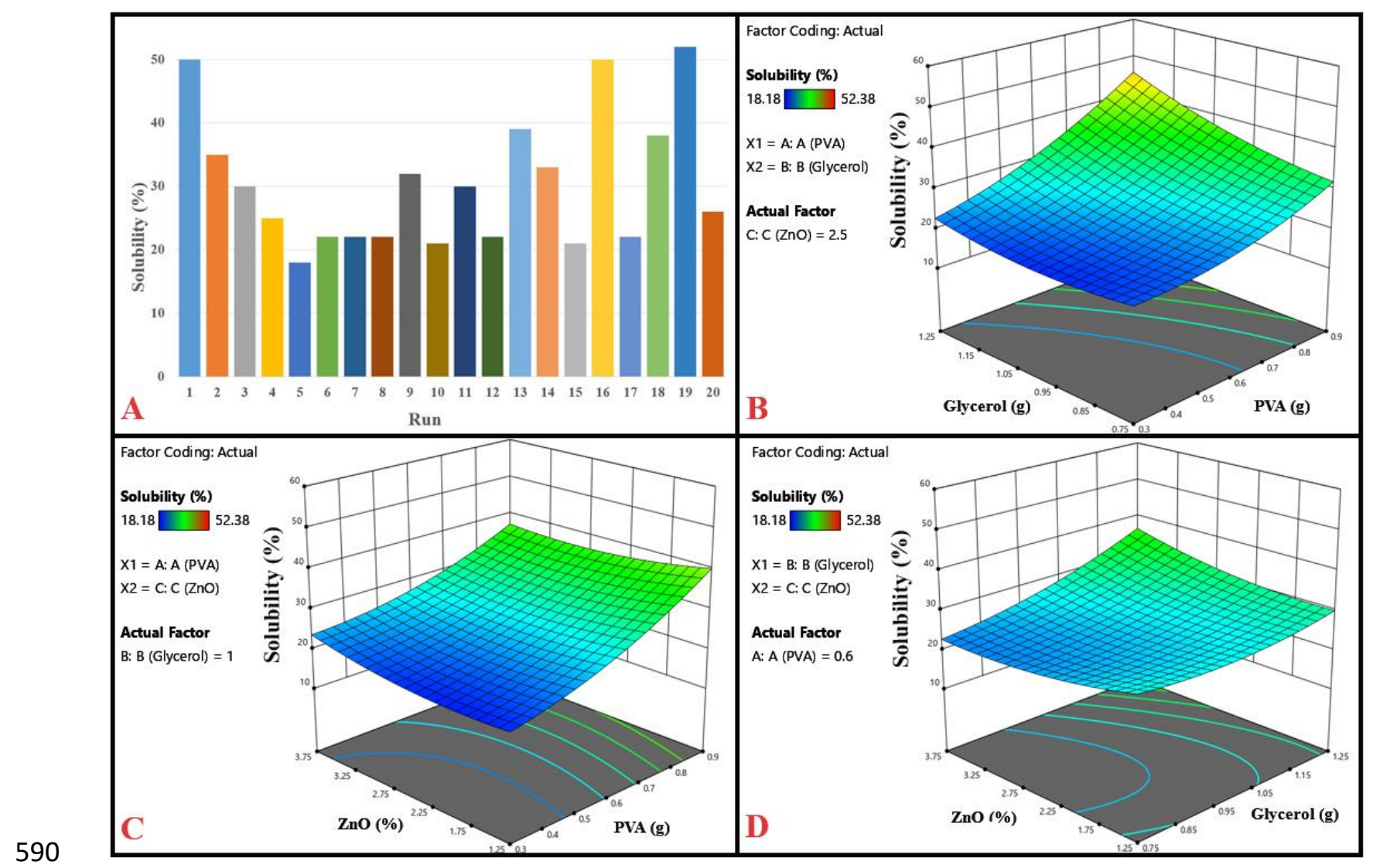

Fig. 7. 


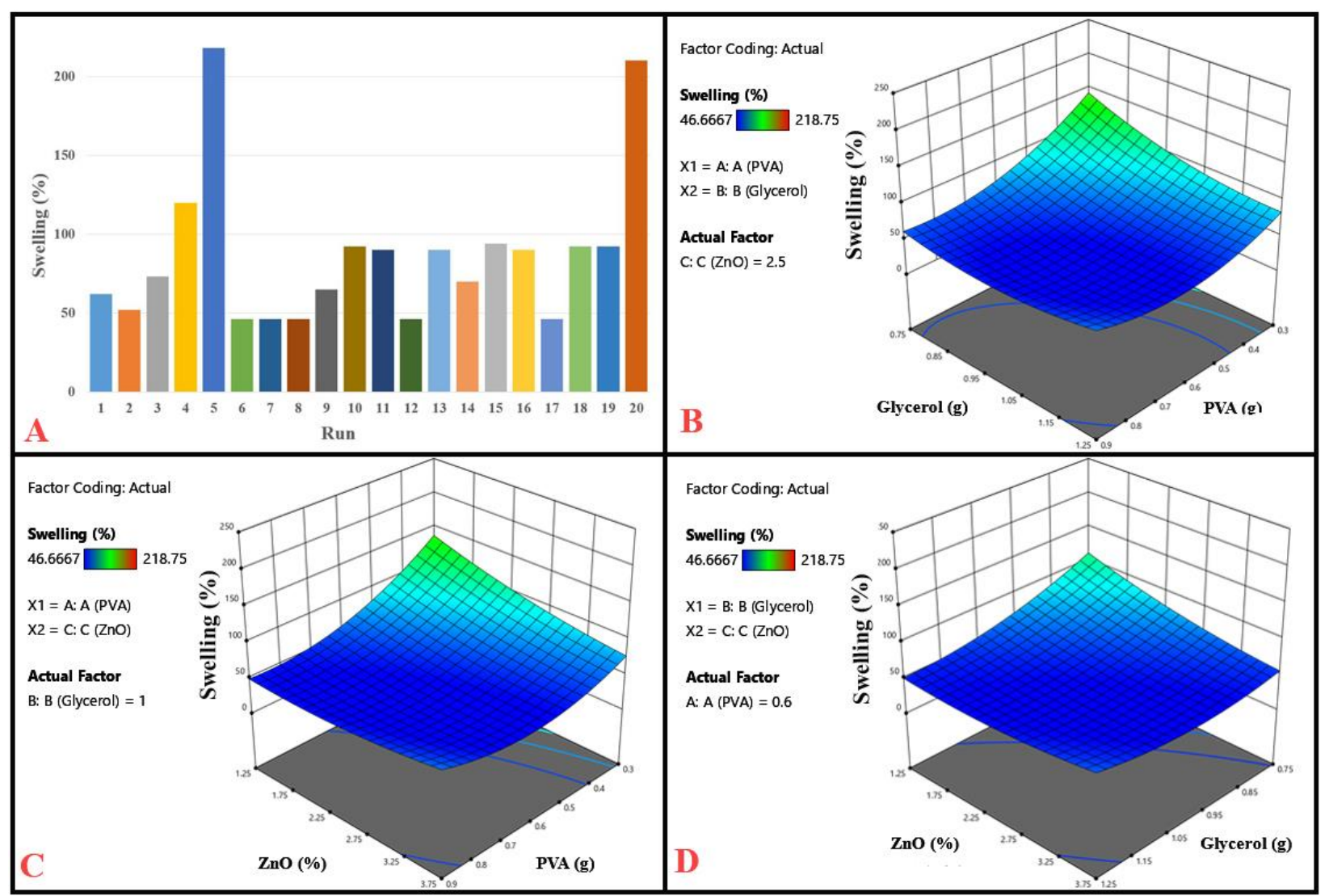

Fig. 8. 

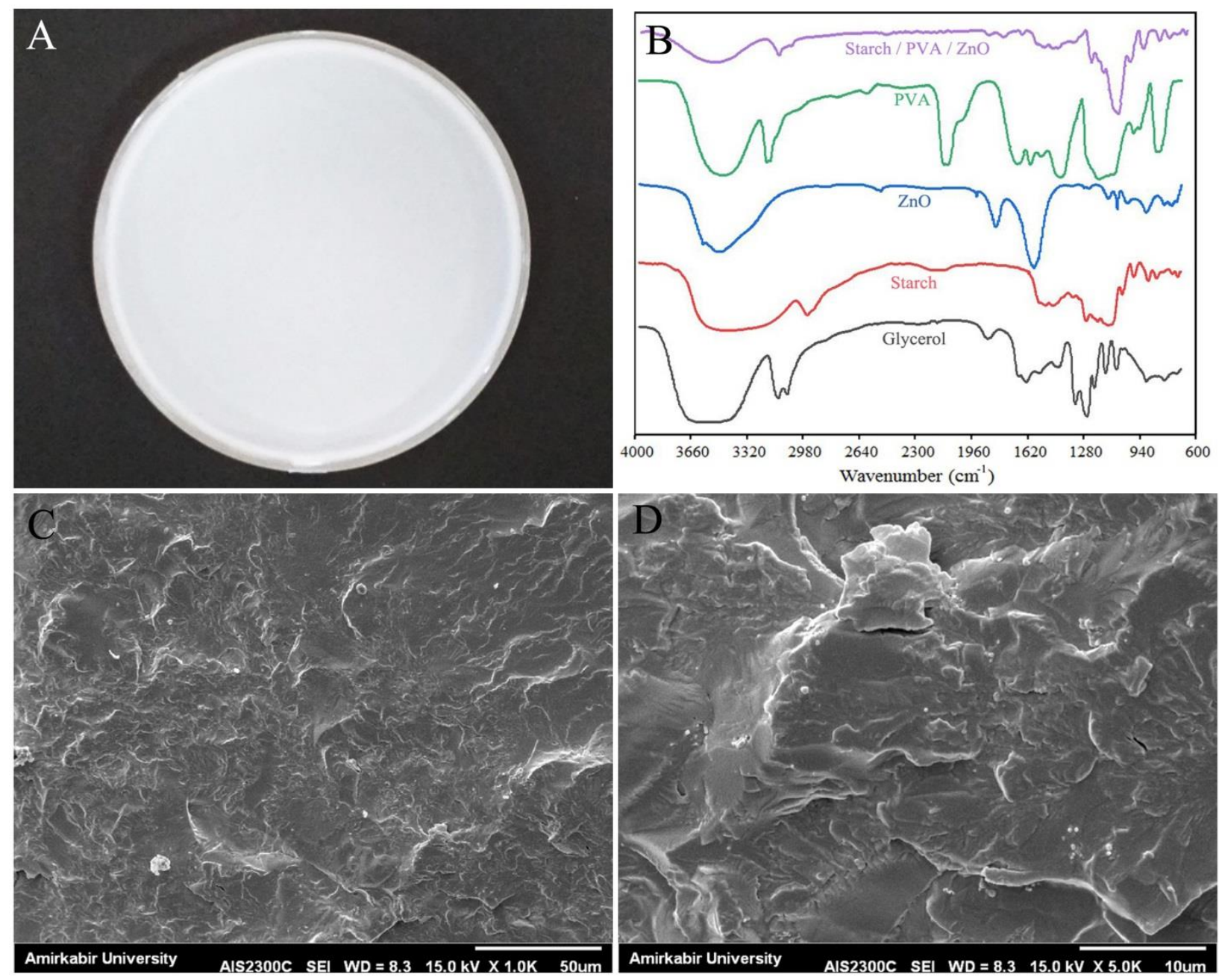

Fig. 9. 


\section{Figures}
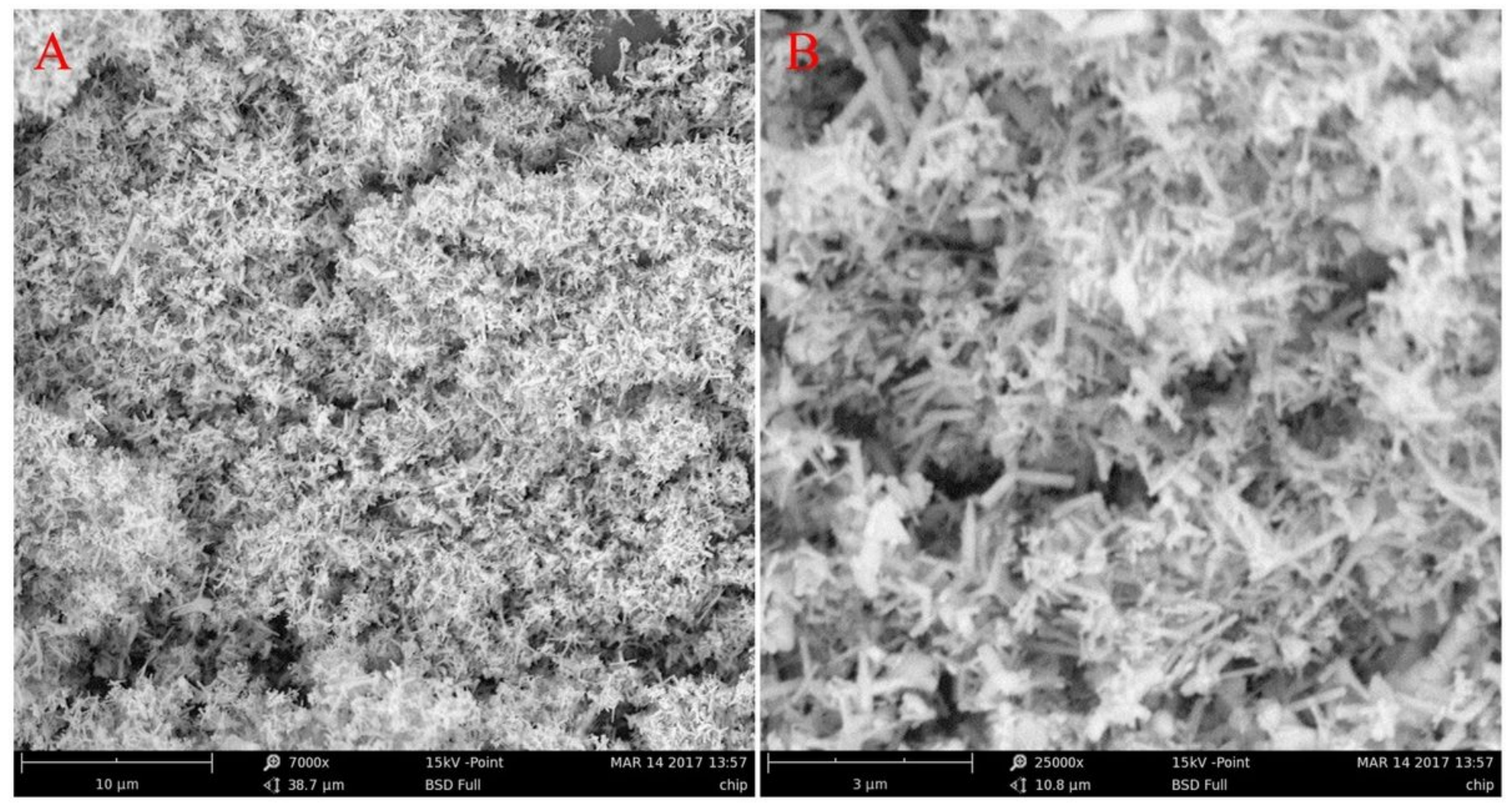

Figure 1

SEM images of $\mathrm{ZnO}$ nanoparticles in two magnifications. 




Figure 2

Images of the appearance of prepared films based on experimental design in different amounts of starch, PVA, glycerol and nanoparticles of ZnO. 


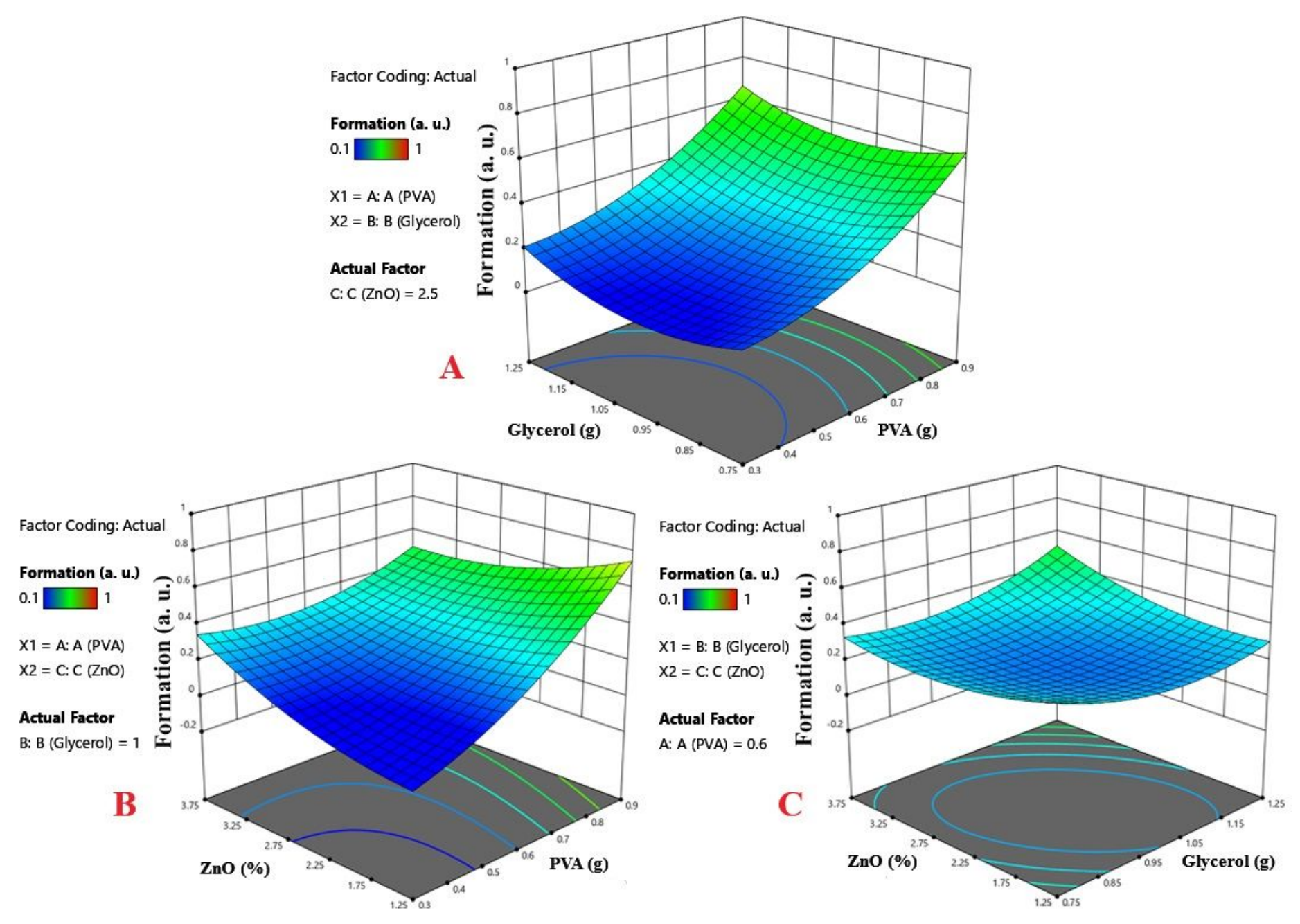

\section{Figure 3}

Three dimensional response surface plots of film formation in the face of change in: (A) Amount of glycerol and PVA; (B) Amount of $\mathrm{ZnO}$ and PVA; (C) Amount of $\mathrm{ZnO}$ and glycerol. 


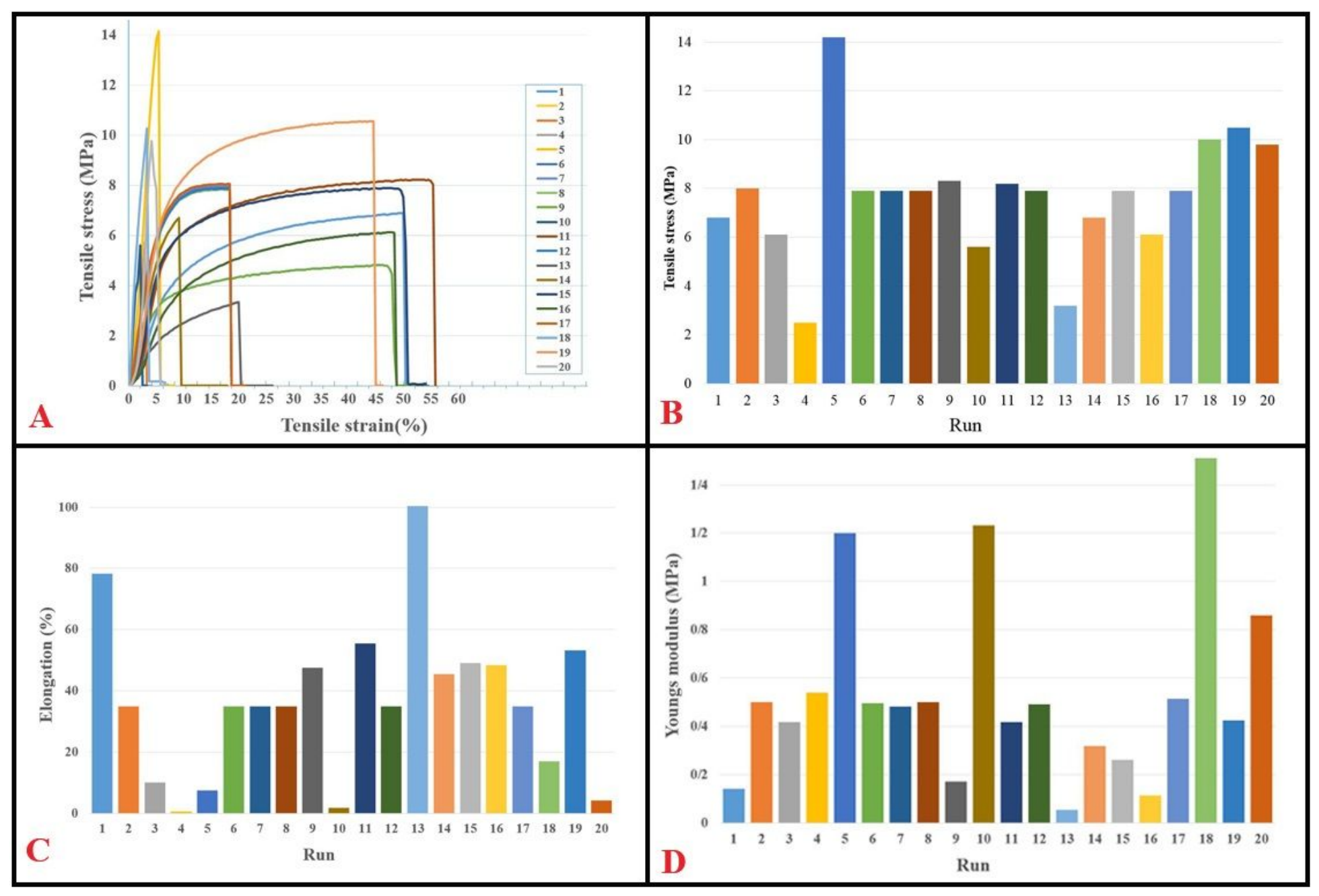

Figure 4

Diagrams of mechanical properties of prepared films: (A) Tensile-Strain diagram; (B) Tensile strength; (C) Elongation at break; (D) Young's modulus. 

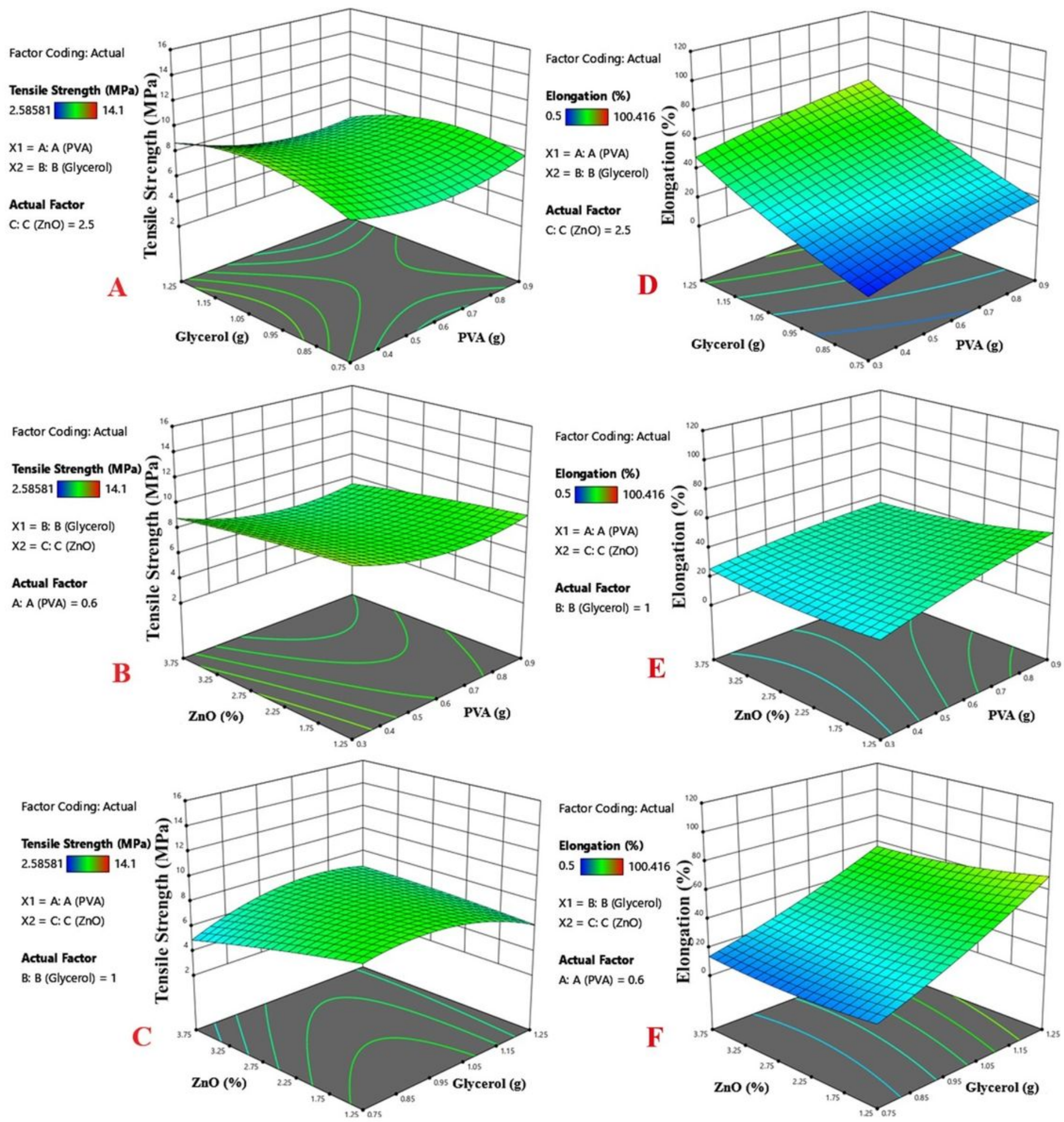

\section{Figure 5}

Three dimensional response surface plots of tensile strength and elongation at break in the face of change in: (A and D) Amount of glycerol and PVA; ( $B$ and E) Amount of ZnO and PVA; (C and F) Amount of $\mathrm{ZnO}$ and glycerol. 


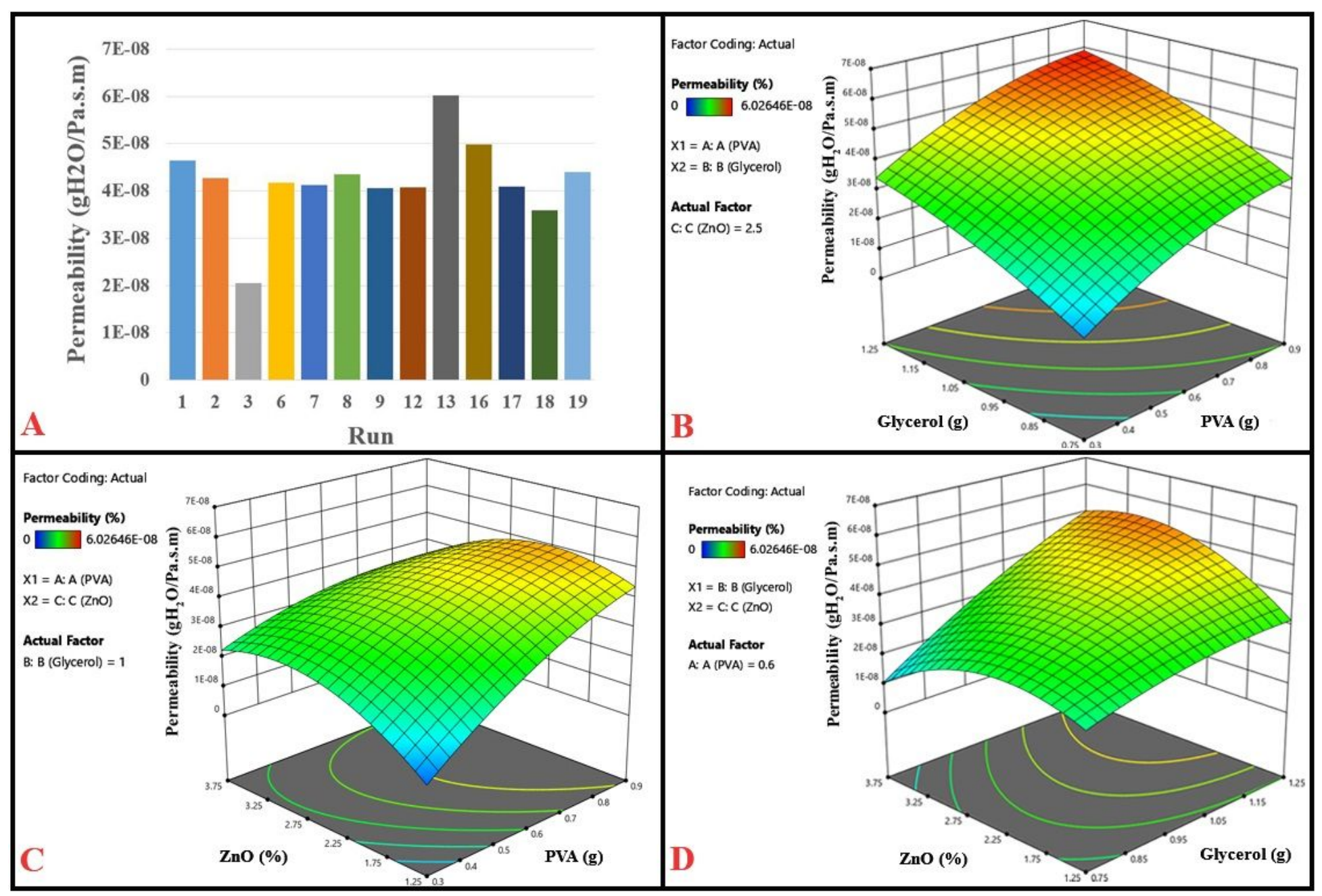

Figure 6

Three dimensional response surface plots of water vapor permeability (WVP) in the face of change in: (A) Amount of glycerol and PVA; (B) Amount of ZnO and PVA; (C) Amount of ZnO and glycerol. 


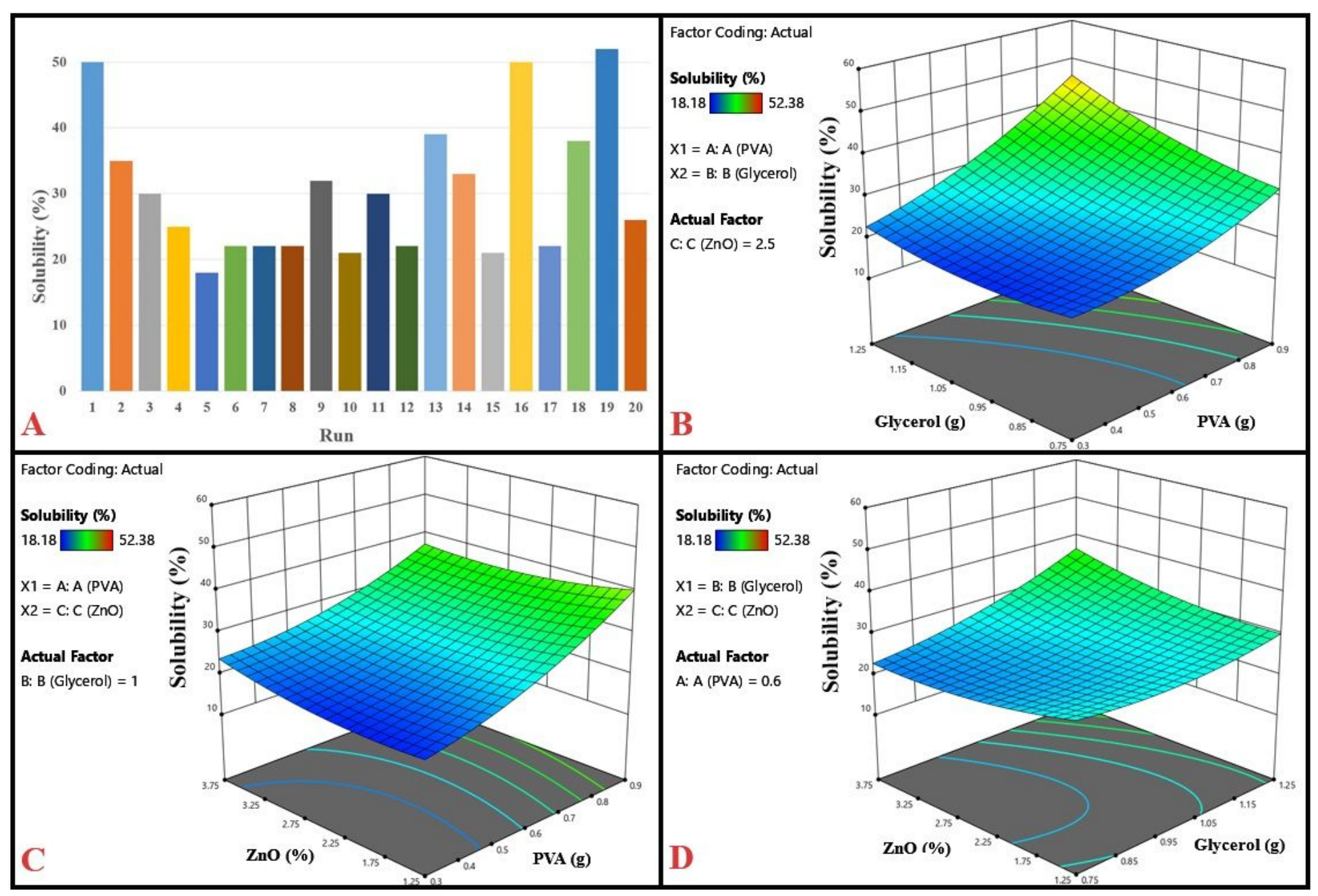

Figure 7

(A) Water solubility of starch/PVA/ZnO nanocomposite films; Three dimensional response surface plots of water solubility in the face of change in: (B) Amount of glycerol and PVA; (C) Amount of ZnO and PVA; (D) Amount of $\mathrm{ZnO}$ and glycerol. 


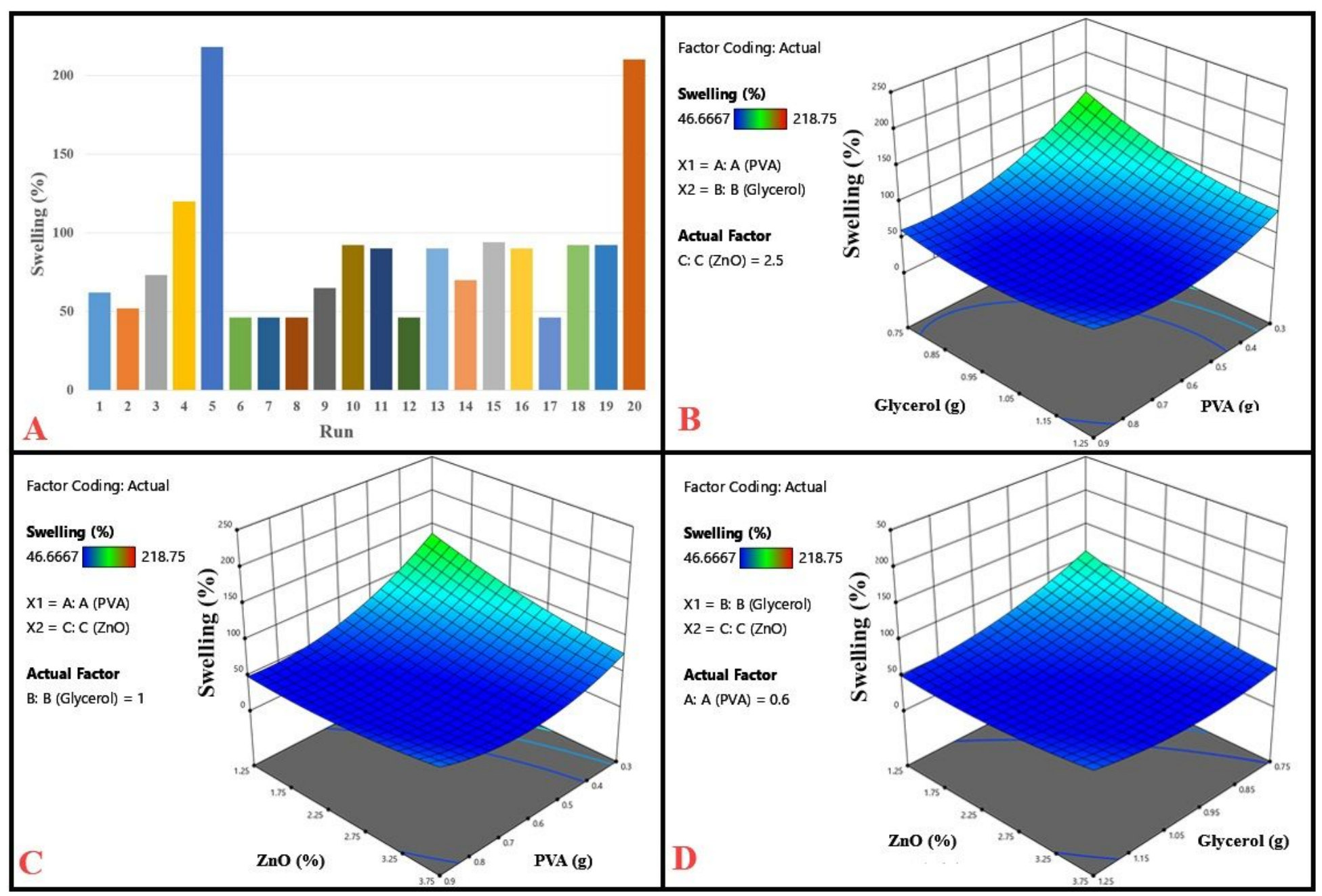

Figure 8

(A) Swelling of starch/PVA/ZnO nanocomposite films; Three dimensional response surface plots of swelling in the face of change in: (B) Amount of glycerol and PVA; (C) Amount of ZnO and PVA; (D) Amount of $\mathrm{ZnO}$ and glycerol. 

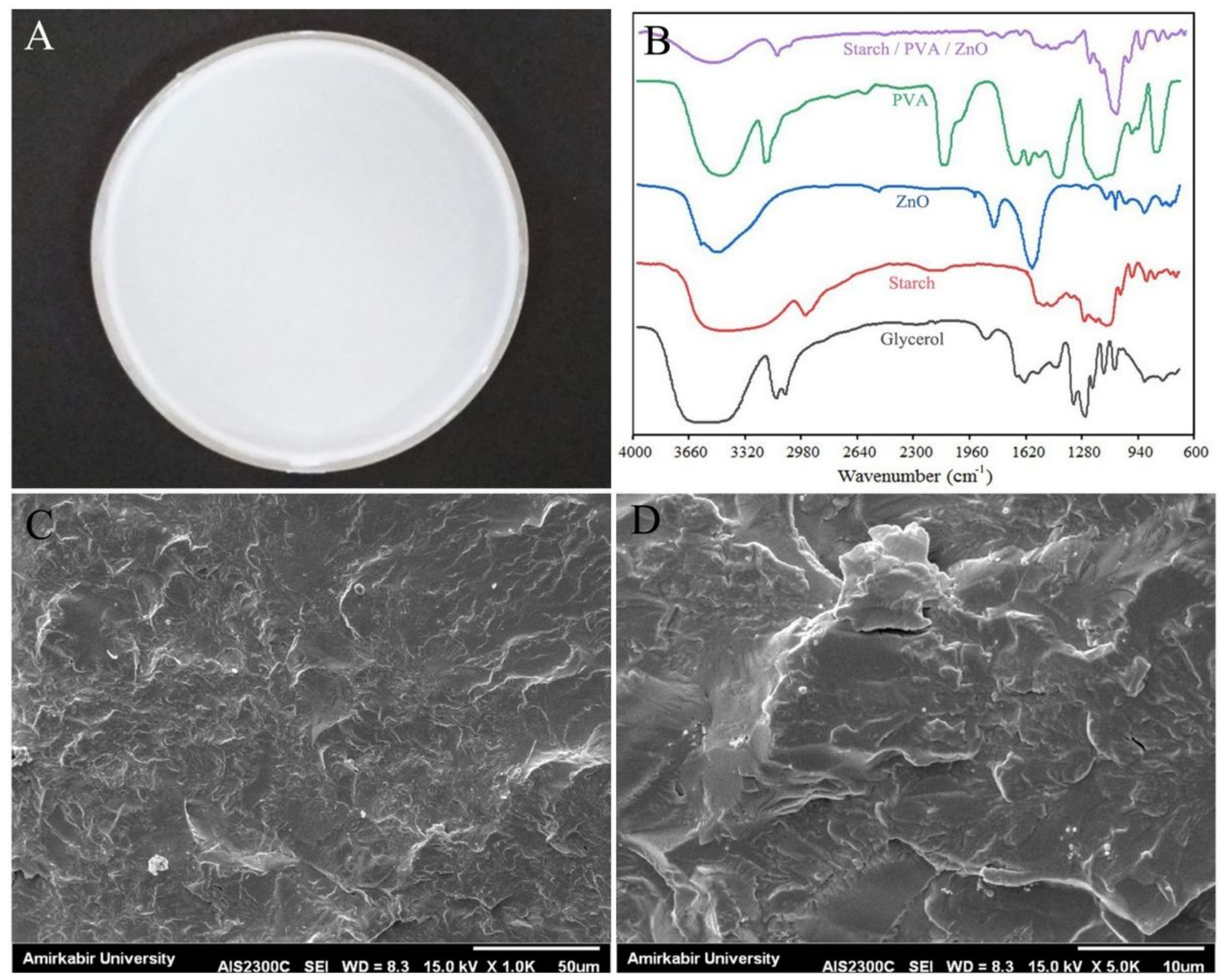

\section{Figure 9}

(A) Prepared optimal film; (B) FTIR analysis of prepared optimal film and raw materials; (C) and (D) SEM images from cross-section of the optimal film in two magnifications.

\section{Supplementary Files}

This is a list of supplementary files associated with this preprint. Click to download.

- GraphicalAbstract.jpg

- SupportingInformation.docx 